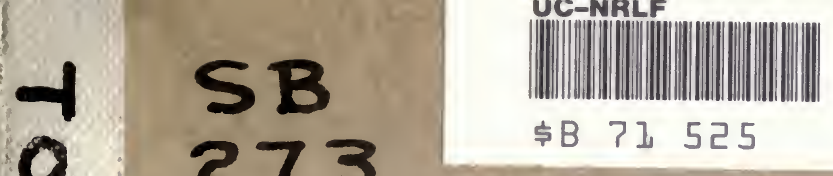
6 64 3
0
0 3
0
0 3
0
0

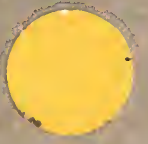

to

U 
s.

1:

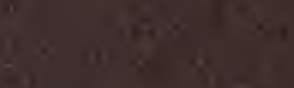

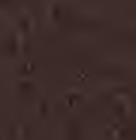
$x=1$

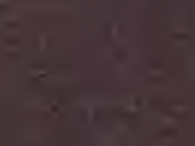

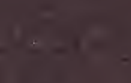
$=1$

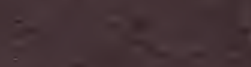
$=x^{2}+1+2 x$

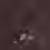




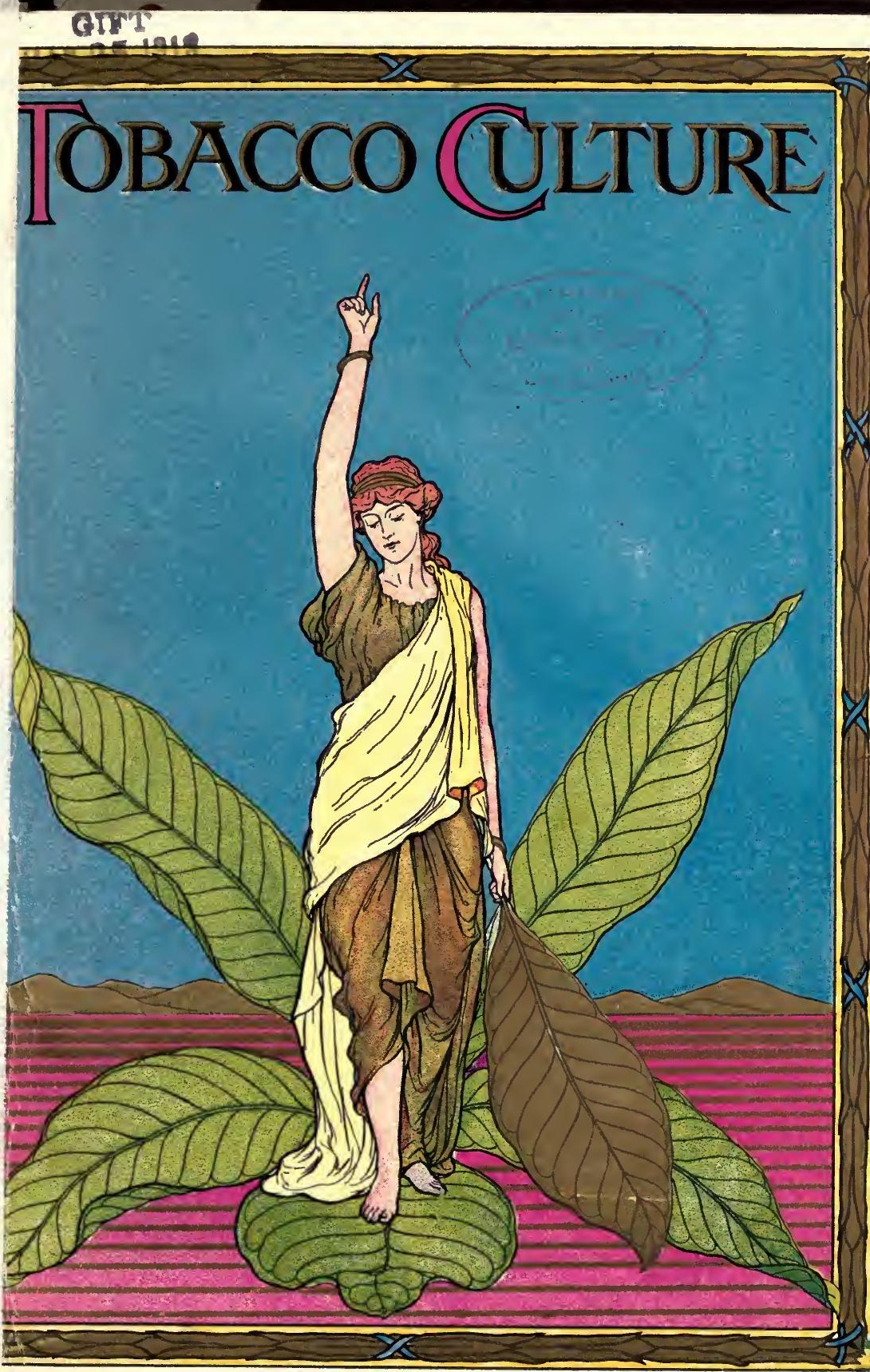





\section{Tobacco Culture}

-

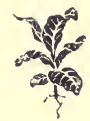

PUBLISHED BY

\section{GERMAN KALI WORKS,}

New York, N. Y. Baltimore, Md. Chicago, IIl. Havana, Cuba 


\section{NOTICE.}

Every farmer can obtain, free of charge, a copy of the following agricultural books:

POTASH IN AGRICULTURE

PRINCIPLES OF PROFITABLE FARMIN

FARMERS' GUIDE

COTTON CULTURE

TROPICAL PLANTING

STASSFURT INDUSTRY

FERTILIZING TOBACCO

FERTILIZING SUGAR CANE

SUGAR BEET CULTURE

SUGAR CANE CULTURE

THE COW PEA

PLANT FOOD

TRUCK FARMING

WHY THE FISH FAILED

FARMERS' NOTE BOOK

STRAWBERRY CULTURE

ORANGE CULTURE

"ALUE OF SWAMP LAND

State which of the above mentioned publications you desire, and it will bé maided to free of charge.

ADDRESS:

\section{GERMAN KALI WORKS.}

NEW YORK. N Y, BALTIMORE, MD, CHICAGO, ILL, HAVANA, CUBA 93 Nassau St. Continental Bldy. 562 Monadnock Blk. Empedrado, 36 


\section{PREFACE.}

The growing of Tobacco has become a large and important industry, especially in Cuba and in rhe United States. In both countries millions of dollars are invested not only in the plantations, but in factories and the manufactured product. Besides, the Tobacco business gives employment to many thousands of people, and the better the crops, the greater their prosperity.

It is believed that this will give the Tobacco grower many "suggestions" which may be of value in a practical way. Thus, there are described the various Plants, Soils and Manures, and how the successful Tobacco planter uses them in order to produce the very best, as well as largest crops, for quality in Tobacco culture is a more important item than quantity.

\section{2}




\section{INTRODUCTION.}

I T IS an interesting fact that three of the most important plants of the world are indigenous to American soil. Two of these, Corn and the Potato, have become important food crops for millions of people, while the third, Tobacco, supplies the world with its most popular and least harmful stimulant-narcotic.

The commercial importance of Tobacco can best be shown by its average market value, which has increased 40 per cent. in thirty years, its acreage being but 30 per cent. greater than it was thirty years ago.

At present, more than 700,000 acres of land are planted each year in this country with Tobacco. According to statistics, the average annual crop amounts to over 600,000 ,ooo pounds, valued at over $\$ 50,000,000$. The Tobacco crop ranks high among the crops of the country in point of value, and the value of the manufactured products of Tobacco for the country has been carefully estimated at over $\$ 200,000,-$ ooo, or nearly one-half the value of our flouring nill products. These and many other facts show the commercial importance of the Tobacco crop in this country. 


\section{CLASSIFICATION.}

The tobacco plant is cultivated over a wide area, or range of territory, owing to its wonderful adaptation to different soils and climates. And yet, it is probably more dependent upon its environment, and more greatly modified in character and in quality by its surroundings, than almost any other cultivated plant. Thus while Wisconsin and Sumatra, Virginia and Cuba, make the production of tobacco special features of their agriculture, and have become centres of its production, still each locality produces its distinctive class or kind of tobacco. The variations in the grade of Tobacco are so clearly the result of soil conditions influenced largely by methods of cultivation and plant feeding or fertilizer used, that they will be discussed separatcly in this book.

The location, soil and climate in which the tobacco crop is grown, and the widely differing properties of these crops lead to very marked differences in cultivation. In the trade there are many sub-divisions for each class, or type, of tobacco handled, but for our purposes here, we will treat of four classes, as follows: (I) Cigar Leaf, (2) Export Tobacco, (3) Bright Leaf and Manufacturing and (4) Perique.

(1) Cigar Leaf. Tubacco for cigar manufacture, includes three different types of leaf, viz, the Connecticut seed leaf, the Cuban, and the Sumatra varieties. Moreover there are different grades, resulting either from crossing or from local conditions of soil, climate, planting or methods of fertilizing employed. 
Cigar tobaccos are grown for tivo distinct purposes, namely: for flavor or aroma, and for texture of the leaf, which properties adapt it for use as cigar wrappers. For aroma, the Vuelta Abajo may be accepted as typical, while for wrapper purposes, Connecticut seed leaf and Sumatra tubaccos are typical.

(2.) Export Tobaccos. These tobaccos include several different types, each meeting various demands of the trade. Usually they are of rank growth, heavy, coarse-grained and strong flavored. They are uscd for manufacturing smoking products required in foreign countries. Their value lies in their strength, as they are cliiefly used in mixtures, either with inferior tobaccos, or with other vegetable adulterants.

(3.) Brirht Leaf and Manufacturing Tobacco. Bright Leaf is produced largely in the Carolinas, Virginia and Eastern Tennessec, and is valuable for its flavor and aroma; its bright yellow color adds to its popularity. It is used almost entirely for pipe and cigarette tobaccos, and for wrappers for plug tobacco. White Burley Tobacco is grown in the Southern counties of Ohio and in the north central counties of Kentucky, and is used for plug tobacco. It is very mild, has a good flavor, and is an excellent absorbent, and for these reasons, it is popular with manufacturers.

(4.) Perique. This tobacco belongs to the coarse, hcavy type of tobaccus. Its distinctive properties are the result rather of the method of curing than of the quality of leaf. It is grown exclusively upon the moist alluvial bottom lands of St. James River, and one or two other Parishes in Louis- 
iana, but its commercial importance is comparatively small. Peculiarities of flavor and furm of marketing, however, make it necessary to consider this class under a speciai heading.

All classes or types of tobacco, belong to a single species, Nicotiana tabacum, closely related to wild and cultivated plants, among which are: the petunia, Irish potato, eggplant, and "jimson" weed.

Tobacco plants of all varieties have much the same habits of growth and characteristics. They grow from three to nine feet in height, possess wide spread, lanceolate leaves attached spirally and alternately to the stalk, at distances of about two inches. The flowers form large clusters with pink-tipped white corollas, which, when grown in masses, present so attractive an appearance, that the plant is frequently grown for purely ornamental purposes.

\section{SOILS FOR TOBACCO.}

While all crops are true to seed, grades are the result of soil differences, peculiarities of climate, of planting and cultivation methods, and of systematic and intelligent fertilization, etc. As the market calls for these distinct grades in tobaccos, this point becomes a very important one for the planter to observe. It is doubtful if an expert could distinguish between wheat, or corn, or potatoes produced in Connecticut, Virginia, Pennsylvania, North Carolina or Wisconsin. Tobacco seed, however, taken from any one of these localities to another, will, in a single season, produce 
a crop so distinct from that of the parent plant, as to be very noticeable, and in a few seasons' growth it will have lost nearly all resemblance to the original type.

Climate cannot be held wholly responsible for these variations nor can they be wholly attributed to the peculiarities of soils. It is worthy, of note that even the chemist's aralysis fails to show such differences in the compositions of these soils, as might reasonably explain the marked changes in the character of leaf, noticed after the transfer of the plant to new localities.

Tobacco growers are well aware that the nature of soils to a considerable degree, influences the color of tobacco leaf ; that the light soils of the Connecticut Valley produce a lighter colored cigar leaf than the richer and darker soils of Pennsylvania; that the dark and heavy soils of Tennessee and Kentucky, produce a heavier and darker leaf than the lighter soils of North Carolina, the home of the famous "Bright leaf" tobacco.

That certain regions are peculiarly adapted to cigar leaf production is good evidence that the nature of tobacco is considerably influenced by the kind of soil. Sumatra, Cuba, Florida, the Connecticut Valley and Wisconsin are centres of "cigar leaf" production, but climatic conditions in the various localities are as different as they are geographically widely separated. The tobaccos grown in these places are often widely different in grade. These differences in grade are not alone a matter of climate, as for example, there is a vast difference between the climate of $\mathrm{Cuba}$ and that of 
Wisconsin, yet both produce good cigar leaf. The time of harvesting and manner of curing have much to do with fixing special types or grades of tobaccos, and even more important is the intelligent cultivation of the plant, and its proper fertilization.

Bearing in mind that growing crops are perhaps as much dependent on the physical condition as upon chemi cal composition of the soils in which they grow, the texture of the soil may be accepted as possessing great influence on the quality of the tobacco produced thereon. Prof. Whitney's investigations showed that soils producing tobaccos of similar type, closely resemble each other in the proportions of the different classes of soil particles. Thus it may be well to compare the proportions of sand, silt and clay in the tobacco soils of the two typical "wrapper" States, and in two typical "filler" States. New York and Massachusetts, and Pennsylvania and Ohio furnish the desired localities.
(Wrapper) New York,
Sand
Silt
Clay
" Massachusetts
$68.8 \mathrm{1} \%$
I $8.18 \%$
$7 \cdot 43 \%$
(Filler) Pennsylvania,
60.10
33.60
$3 \cdot 3$ I
66
Ohio,
17.27
49.02
29.27
$23 \cdot 3 \mathrm{I}$
44.01
$27.5^{2}$

The close resemblance between the physical properties in each of these two groups is apparent. The great dissimilarity between the properties of the two groups is equally plain. These facts partly explain the similarity of grade and character between tobaccos of New York and the Con- 
necticut Valley, and those of Pennsylvania and Ohio ; also the marked differences between tobaccos of the "wrapper" states, and those of the "filler" states.

The work of Prof. Whitney demonstrates another fact of great importance affecting the practical details of tobacco culture. He appears to have conclusively proved that the character of the tobacco produced by any soil, depends to a marked degree upon the average mean moisture of the soil. When this point has been more carefully studied, and is more fully understood, it is probable that the usefulness of a soil for growing any particular kind of tobacco can be determined with a reasonable degree of certainty.

A good illustration of this condition is supplied by the results of the moisture records of the soils at Quincy, and Fort Meade, Florida, two widely separated localities, with soils superficially quite different, yet producing nearly identical grades of cigar tobacco. Investigation showed the moisture of one of these soils to be 8.26 per cent, and of the other to be 8.6 per cent. The closest approach in character of tobacco to that grown in these localities by any other region of the country is the Counecticut Valley, where the average moisture is found to be about 7 percent. It is quite probable that the recognized value of natural forest growths, as indicators of good-tobacco soils, depends on this relation between plant and average water supply.

The "wrapper" producing soils of Connecticut Valley, Florida and New York are fine in texture, light in color and low in moisture. They are strongly sandy in character, av- 
eraging over 6o per cent. of clear sand, but contain very little (less than 3\%) clay. They are, therefore, early lands, easily worked, warm and responsive.

The "binder" and "filler" soils of Pennsylvania, Ohio and Wisconsin are heavier in character and finer in texture. They contain about 20 per cent. moisture, an average of say 25 per cent. clay, and from 30 to 35 per cent silt. They are consequently more fertile, more generally productive, later, slower, and harder to cultivate, than are the soils producing the lightest cigar leaf.

The "Bright Leaf" soils of North Carolina and Virginia are sandy to a depth of from one to ten feet, always underlaid by a heavy clay sub-soil. The surface soil averages 8 to 9 per cent. clay, about 15 per cent. silt, and nearly 60 per cent. sand. These soils are not fertile or productive, though easily worked, early and quite liable to drouth.

"Export" tobaccos come from heavy, fertile soils, containing high percentages of silt and clay, with considerable iron, and pebbly material. These soils are stiff, but easy to work when properly broken. They hold moisture, and are slow and late.

The White Burley soils contain a large percentage of carbonate of lime, and they are filled with small particles of limestone rock, which contains a considerable amount of phosphate of lime. These soils are not so stiff as the soils adapted to the growth of heavy shipping tobacco.

The "Perique" soils of Louisiana, differ greatly from all other tobacco soils, as much so as the product itselt. 
Their cultivation differs also from that of other tobaccos. These soils are deep, alluvial bottoms, dark in color, fertile, fine in texture, and contain about one-fourth part of sand. They are easily worked and high in moisture.

\section{THE SEED.}

The quality of seed from which tobacco is to be grown is of the greatest importance. This is because the quantity of the yield (with most kinds of tobaccos,) is of less importance than the quality of the crop. In other words, quality of each class of leaf usually regulates its value. Seed plants should be grown from first class seed only, and each kind by itself. When different kinds are grown close together, they mix badly, though in outward appearance the plants give no indication of this mixing.

The practice of growing seed plants by themselves is necessary because tobacco has a decided tendency to depart from fixed types, and to adapt itself to local conditions, through its extreme sensitiveness to climate and soil conditions. The pollen of the plant is carried long distances, and the presence of different types of tobacco nearer than a mile from the seed plants is likely to result in mixing, or crossing of varieties, a condition which usually results in deterioration. The seed plant should not be allowed to develop suckers, and the seed pods should be bornc only upon the main stem of the plant. When seed plants are grown by themselves, only perfectly developed plants, with all distinctive qualities of the leaf, should be reserved for seed 
purposes. A few of the upper leaves of the plant should be removed for the purpose of preventing injury from storms, or wind, and also in order that the entire vigor and strength of the plant may be devoted to the perfection of its seed, rather than for the development of the leaf.

Only the earliest maturing seed pods should be allowed to ripen, and all others should be removed before maturity. What the planter thus loses in quantity, he makes up in quality. However, the number of seeds developed in a single pod is enormous, reaching as high as 5,000, and an ounce of clean seed will easily contain from 300,000 to 400,000 individual seeds. After the pods have turned brown (thus indicating ripeness) they should be cut with the stem on which they are borne, and preserved in their natural condition, protected against air and moisture, and kept at a temperature varying as little as possible, until needed for sowing.

The selection of seed should be regulated by the variety or character of crop desired, bearing in mind that this latter feature is controlled largely by the soil and climatic conditions of the locality in which the crop is to be made. The seed should be bright, hard, and free from chaff and impurities. Cuban growers retain a large admixture of chaff with the seed as a protection against mould and deterioration. Seeds remaining in the pods, if well dried and bottled, should not be susceptible to deterioration or mould. The Cuban practice is not a desirable one to follow, and it seems to be the result of careless practice, or crude and imperfect 
methods of separation and cleaning. Thus, a given weight of Cuban seed only contains one-half the quantity of actual tobacco seed as the same quantity of seed, when cleaned and prepared for market by American methods would yield.

\section{TESTING THE SEED.}

All seeds, tobacco seeds included, have their periods of iongevity, or vitality, beyond which the germinating power, or life of the seed begins to wane and finally disappears. Many authorities claim that the vitality of tobacco seed may reach ten, or even fifteen years, but it is a well established fact, that deterioration begins after the fifth year, so that beyond that time its use involves a risk and possible loss.

Therefore, no seed of unknown age should be used until first given a germinating or other test.

This is done by dropping some of the seed upon a hot stove or shovel; good seed will burst or pop. Any seed not affected in this way, may be counted as bad, and should not be used for sowing. The seed may also be tested by actual germination, thus:-sprinkle the seed into a small mass of cotton wool in a tumbler, which should contain a little water in the bottom. If the tumbler be then kept in a warm place, at the end of three or four days, all the good seed should germinate. The proportion of unsprouted seed will then indicate the relative percentage of bad seed present in the lot.

Another satisfactory way of testing seed is to take a small piece of board covered with a piece of cotton cloth 
che ends or edges of which dip into water. Sprinkle the seed to be tested over the surface of the cloth thus raised above the water, and keep in a warm place. At the end of five days time, all good seed will have sprouted, and ky counting the unsprouted seed, the actual proportion of bad seed can be accurately determined. It is not necessary that seed tested by either of these methods be finally discarded unless the proportion of bad seed is very large, for by knowing the amount of bad seed present, enough seed may be used to secure a full stand and crop.

\section{GERMINATION.}

Under certain conditions it may be desirable to gain time by germinating or sprouting the seed before it is sown. This may be done by taking a strip of cotton cloth about six or eight inches in width, sprinkling the seed evenly over this surface, and then rolling the cloth into a compact roll. If one end of this strip be placed in a basin or tumbler containing a little water, the roll of cloth will absorb moisture as a lamp wick absorbs oil. If the roll is kept constantly moist, the seed will germinate, and if carefully removed from the cloth as soon as sprouted and sown in a prepared seed-bed, a few days time will be gained. Grẹat care however, is necessary not to injure the tender, young sprouts, and the danger of such injury is so great that this method is only to be recommended in exceptional cases.

Another good way is to sow the seed in a box, or pan of earth, which is watered daily and kept in a warm place, 
either in the sun or near a stove. When the seed in the earth has sprouted, the entire mass may be sown in the same way that ungerminated seed would be sown when mixed with earth, meal or other material recommended in the sowing of seed

\section{THE SEED BED.}

The use of the seed bed is two-fold: First, to gain time in starting the crop, and second, to furnish better protection to the young plants than is possible with field planting. As the first need in the selection of the seed bed is warmth, a protected and sheltered spot with Southern exposure is best. In the northern states, a wall, a building or fence is utilized for shelter. In the south, planters, take advantage of the presence of a strip of woods. Fine, warm, mellow, thoroughly pulverized soil is necessary. In the south, new ground is preferred; in the north, old ground. The same place may be used year after year for the seed bed. In the southern states, particularly Florida, where Cuban methods are closely followed, the ground selected for the seed bed is previously burned over by laying sticks of wood or small logs lengthwise on the bed, and covering the same with brush or light dry wood. When the soil has been thoroughly heated for about half an hour, the fire is removed, and put on another part of the bed.

The object of burning is first, the destruction of weed seed, and secondly, to improve the mechanical condition of the new land to be used for the bed. It is a question if either 


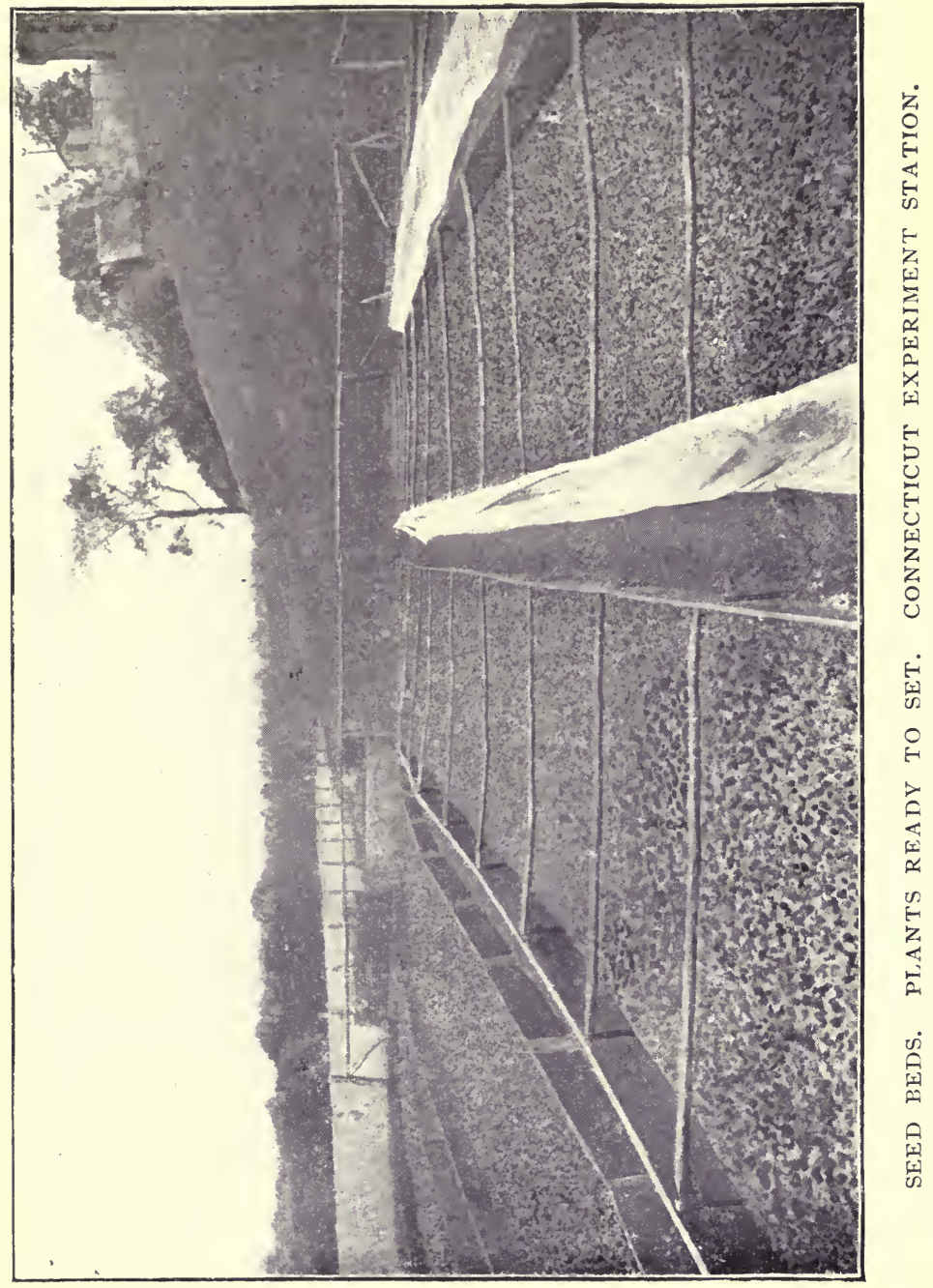


of these two objects is important enough to warrant the considerable cost involved, and this plan is being gradually abandoned by tobacco growers in the north. Burning is still practiced in Kentucky and Tennessee, where nearly half of the tobacco crop of the United States is raised. The growers there still think burning the land a necessity. Burning the soil is supposed to aid in breaking it up. A small quantity of wood charcoal from the incomplete burning of the wood is added to the soil, and also considerable quantities of available potash are supplied by the ash of the burnt wood. The land is burned until it has a reddish cast.

A great many growers in selecting a place for the seed bed, plan to have it near water, and, if possible, so located that the beds can be irrigated. In Florida especially, a very dry spell of weather of ten occurs at the most critical period of the plants' growth, late in April, and through May. Irrigating the beds is the surest way to success in growing plants. This irrigation differs somewhat from the ordinary methods, in that the water furrow or trench is made along on the outsidc of the bed. No water is allowed on the bed, and tine plant simply gets the water through the natural drainage of the soil, as care is taken that this water trench is on a higher level than the bed.

Preparation of the Bed. The location having been decided on the first step in preparing the bed for the seed depends somewhat on the size and shape of the bed. Long narrow beds are the best shape. The width should not exceed four feet, and the length will depend on the amount of 
land to be used. For a large area, a uniform width should be used; narrow beds with walks, being the most cconomical shape, since by this means, every part of the bed is accessible either for working or removing plants. The same plan may be followed with a square bed by subdividing it. into narrow four foot beds, as is done in the heavy tobacco districts, where some of the beds cover I,600 square yards.

The ground should be thoroughly plowed, dug with a mattock or spaded, and then made as mellow as possible by the use of the harrow rake, or hand cultivator. The surface should then be smoothed over with a garden rake, and all litter, unbroken lumps, and other incumbrances removed. Only chemical fertilizers which are quick acting and free from weed seed should be used. These should be applied broadcast, and raked in. The first application should be light, as it is desirable to apply fertilizer in the form of solution from time to time during the growth. of the plants. Thorough raking with an ordinary garden rake is the most effective way of properly fining the soil, and in finishing off this raking process the rake should be carefully drawn across the bed evenly as possible, thus leaving very small furrows from its teeth in the fine soil. The seed is sown in these furrows. Seed thus sown will come up in perfectly uniform rows, and after the plants put on their second set of leaves, the bed may be gently raked, so as to break any crust formed after rains, and to loosen the soil about the young plants. 


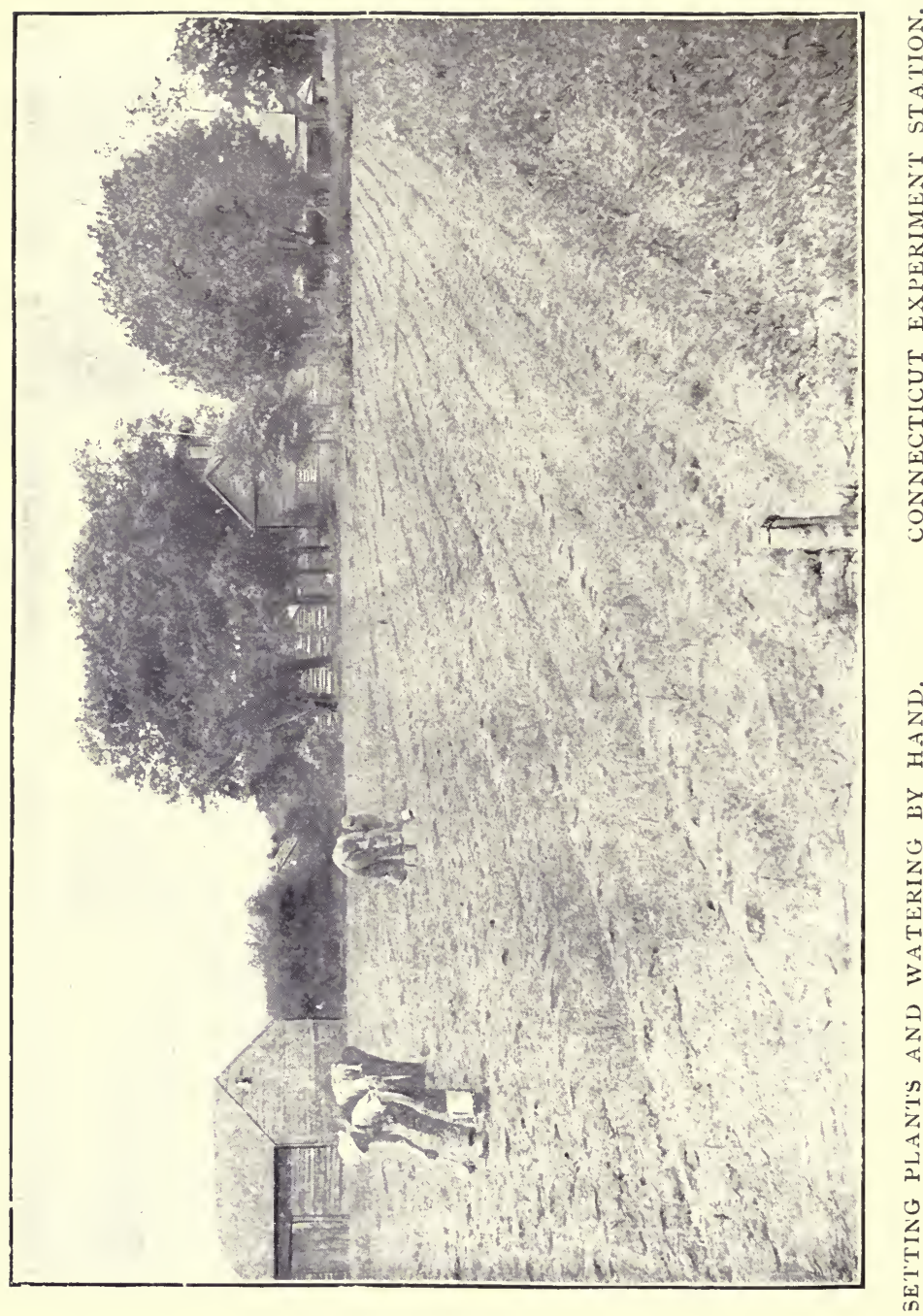




\section{SOWING.}

The seed selected and previously tested should be mixed with some foreign material before being sown. There are two reasons for this course. First, the seed is so small and dark colored, that it is not easily seen after it has been sown. Therefore, a light colored, foreign substance should be mixed with the seed, and then the area covered will be shown up, and any unevenness in the work can be remedied. The second reason for mixing with foreign material is on account of the extreme minuteness of the seed. A small quantity is sufficient for a large area, and without the admixture of other material, an even sowing of the seed is extremely difficult.

For mixing purposes, corn meal, plaster of paris or flour may be used. The seed should be carefully sown by hand, and by going over the ground in two directions at right angles to each other, even sowing of the seed is assured. A good method for mixing the secd with the soil is by treading it in by foot, but for large areas, the hand roller should be used.

\section{AMOUNT OF SEED.}

The quantity of seed required per acre of ground varies very materially. The allowance of seed should be one ounce per acre of land, and this quantity will cover a bed about 40 square yards of surface. 


\section{PROTECTION.}

The beds are generally protected from birds, insects and cold by being covered with a layer of brush. Muslin cloth, however, is now extensively used for this purpose, being stretched over the bed from side to side and tacked to logs or planks, thereby raising it high enough above the bed to clear the growing plants. The cloth cover must be taken off occasionly for weeding or fertilizing the bed when the plants are ready for the field. Not only insects and other enemies of the plant are thus prevented from attacking the young plants, but the additional warmth secured to the bed by the radiation of the soil heat hastens the growth, and makes earlier transplanting possible. It is not necessary to remove the muslin cover of the bed to water it, as it can be thoroughly watered by using a sprinkler. The advantage of watering through the muslin is that the moisture of the cloth helps to keep the bed moist longer than if the cloth were removed, and replaced immediately after watering.

\section{THE CROP.}

The location, the climate, and the soil in which the crop is to grow will decide the class of tobacco to be cultivated. The type or variety, however, is dependent on these conditions, and also more or less on individual notions or desire of the planter, knowledge of the kind grown, facilities for working the soil, etc. Thus the Florida grower has the option of growing either Sumatra, Cuban, or Florida Speckled Leaf, while in the Connecticut Valley, it may be either Seed leaf or Havana seed. 


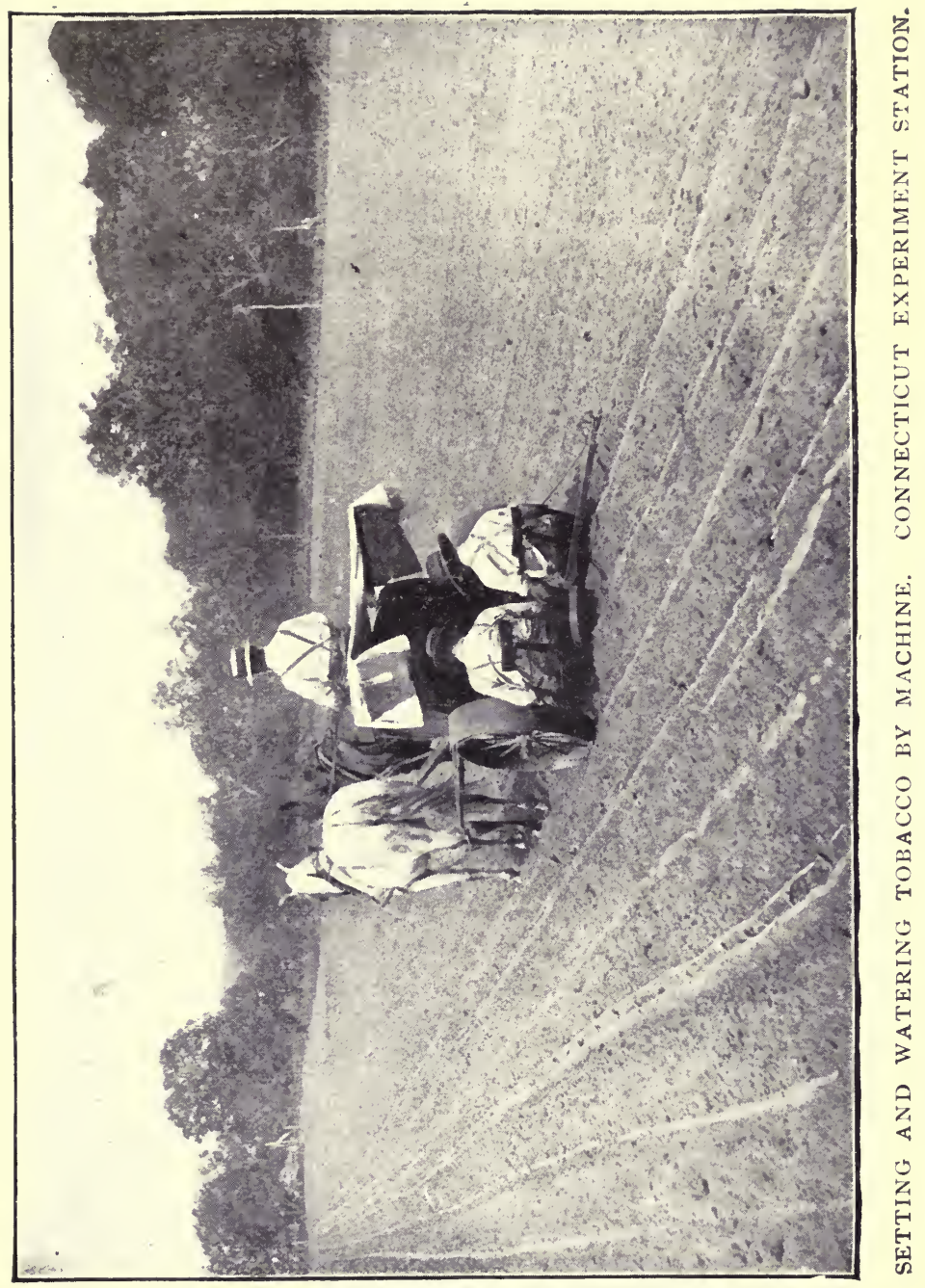




\section{PREPARATION FOR THE CROP.}

In New England the common practice is to select for tobacco, land which is intended to remain fur years in this crop. This is only possible by very heavy fertilizing. But the New England grower claims that this gives him more perfect control of the crop, whereby he can feed it directly for the qualities worth most in the market. It is, therefore, no difficult matter to find in the Connecticut Valley fields, that have produced tobacco annually for from ten to twenty years, with improvement in quality of product, and no diminishment of yield. The Pennsylvania grower has his favorite tobacco fields, but practices rotation of crops for which his heavier soils are adapted. In the South and West, rotation of other crops with tobacco is the rule. The Southern grower of heavy shipping tobacco, as well as of cigar leaf, however, uses new soil for tubacco, and then takes two or three leaf crops from the soil before changing the crop. The grower of Burley tobacco also prefers new land, but after two crops, he rotates with grain and grass. The Bright Leaf tobacco is generally produced on old land, put out in tobacco every third year.

The question of when to piow tobacco land next arises; fall or spring are the two seasons for plowing. No rule can be laid down, though the methods of successful growers of each kind of tobacco afford a safe guide. Generally speaking, heavy clay soils require fall breaking, so as to be further broken up by the frosts of winter.

In cigar leaf regions, fall plowing is almost universal, 
except in Florida, where early spring plowing, usually in February is the rule, followed by a later plowing, immediately preceding the putting out of the plants. The coarser kinds of fertilizer are distributed in the furrow at the time of the first plowing, and covered by the next trip of the turn-plow.

In Pennsylvania, Ohio and Wisconsin, the turning under of "stubble" or sod immediately after harvest or haying is a favorite practice. In the south, manure is frequently applied broadcast, previous to this plowing. A second plowing is the rule just before final freezing of the ground occurs and tobacco stalks, "chopped," are turned under at this time. The best growers plow in the spring some two weeks before the planting.

Growers of Bright Leaf favor deep breaking in the fall, usually with two-horse plows. This is followed in February by shallow furrowing with the "scooter," at which time the manure, litter and any coarse fertilizer to be used, is covered in the furrow. In the region where heavy shipping tobacco is raised, successful planters believe that most of the cultivation should be done before the plants are set out. Deep fall breaking with heavy turn-plows, is general. This breaking should be so early that vegetation turned under may be still green, for then its decomposition is hastened, and its fermenting action in the soil is increased. In early spring the manure is applied broadcast and turned under by a second but more shallow plowing.

Burley Tobacco is mostly grown on land broken in the 


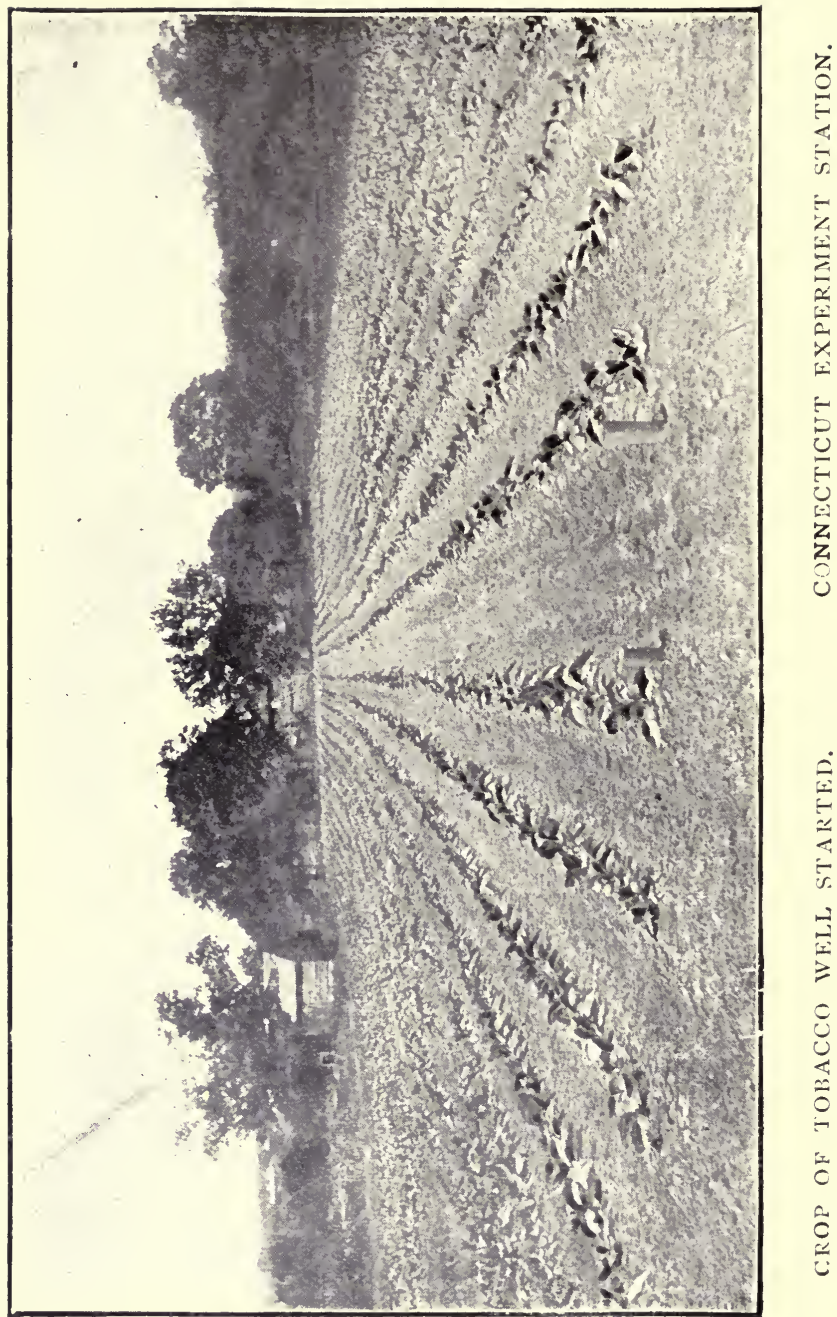


early spring; a sod usually being turned under, unless the land be new, in which case two or three, successive crops of tobacco may be grown. The soil is fined chiefly by the use of the disk harrow, in April or early May.

The Perique grower plows twice; first in January when the land is broken about eight inches in depth, as soon as dry enough for the purpose. In February, beds four or five feet wide are throwr up and later smoothed by means of horse rake or harrow. Just previous to planting in March, other beds are turned on top of these and smoothed by hand rake. On these beds the plants are set by hand. The methods of fining the land are about the same in all the tobacco growing districts.

Tobacco is usually produced by growers who make its cultivation a specialty. They are, like all specialists, intelligent and painstaking. They use in their work every improvement determined by field practice, and study the suggestions of scientific men. Thoroughness of cultivation is recognized among all intelligent growers as indispensable to success.

For Cigar tobacco, everywhere except in Florida, the last plowing is usually followed by the disk harrow, and the fertilizers spread broadcast are then harrowed in, and the surface brought to the desired fineness by the smoothing harrow. If hand planting is practiced, a ridger is used for throwing up slight beds and marking off the spaces for the plants. Where a transplanter is used, which is now almost universal except among the growers of real Cuban and Sum. 
atra leaf, the smoothing harrow fits the soil for the plants.

In Florida the closeness with which the Cuban and Sumatra plants are set in the rows, (for increased thinness of leaf) prevents the use of the transplanter, which has heretofore not been gauged more closely than 18 inches. When plants are set as closely as 8 inches in the row, (which is not uncommon among Cuban growers), extremely rapid planting can hardly be done with a machine worked at the speed of walking horses.

The Cuban grower in Florida plows and cross-plows, the latter working of the soil preceding the transplanting by some three weeks. Just before setting the plants, the harrow is used until the ground is thoroughly pulverized. The "scooter" is then used for running furrows two and one-half feet apart, into which the fertilizer is scattered and then covered by the turn-plow, running back and forth. The plants are then set on the ridge thus made.

The grower of Cuba leaf in this country has moditied this practice by placing his rows from three to three and one-half feet apart for Cuban, and four feet apart for Sumatra leaf; and this makes horse cultivation possible. However, he grows as many plants to the acre as does the Cuban planter, by placing them nearer together in the row. The most successful way of transplanting tobacco in Florida is, by running furrows with a small Scotch plow about $5 \frac{1}{2}$ feet apart, and setting the plant in the bottom of the furrow. This insures a perfect stand, and the plants being down below the surface are not apt to be destroyed by cut- 


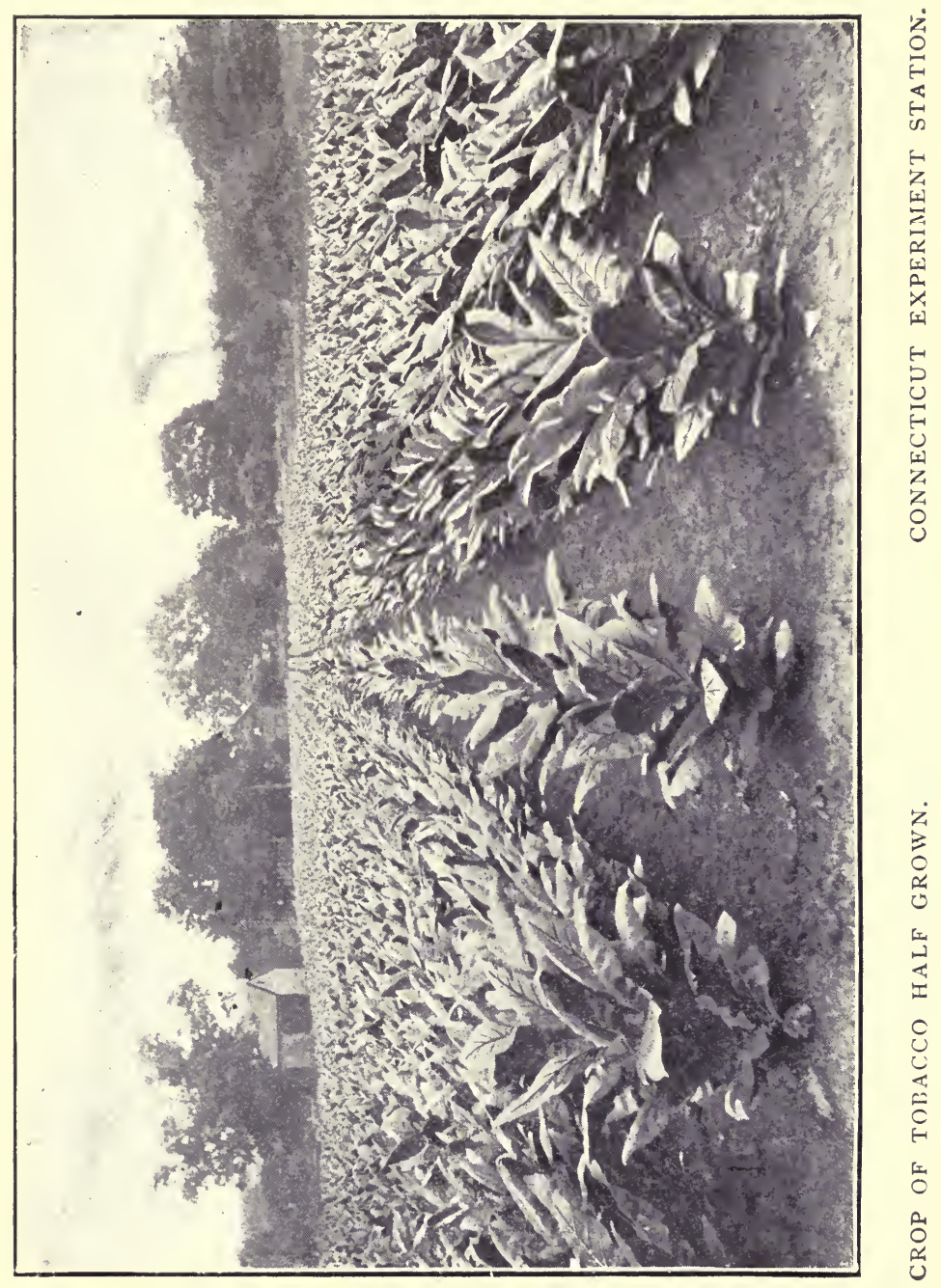




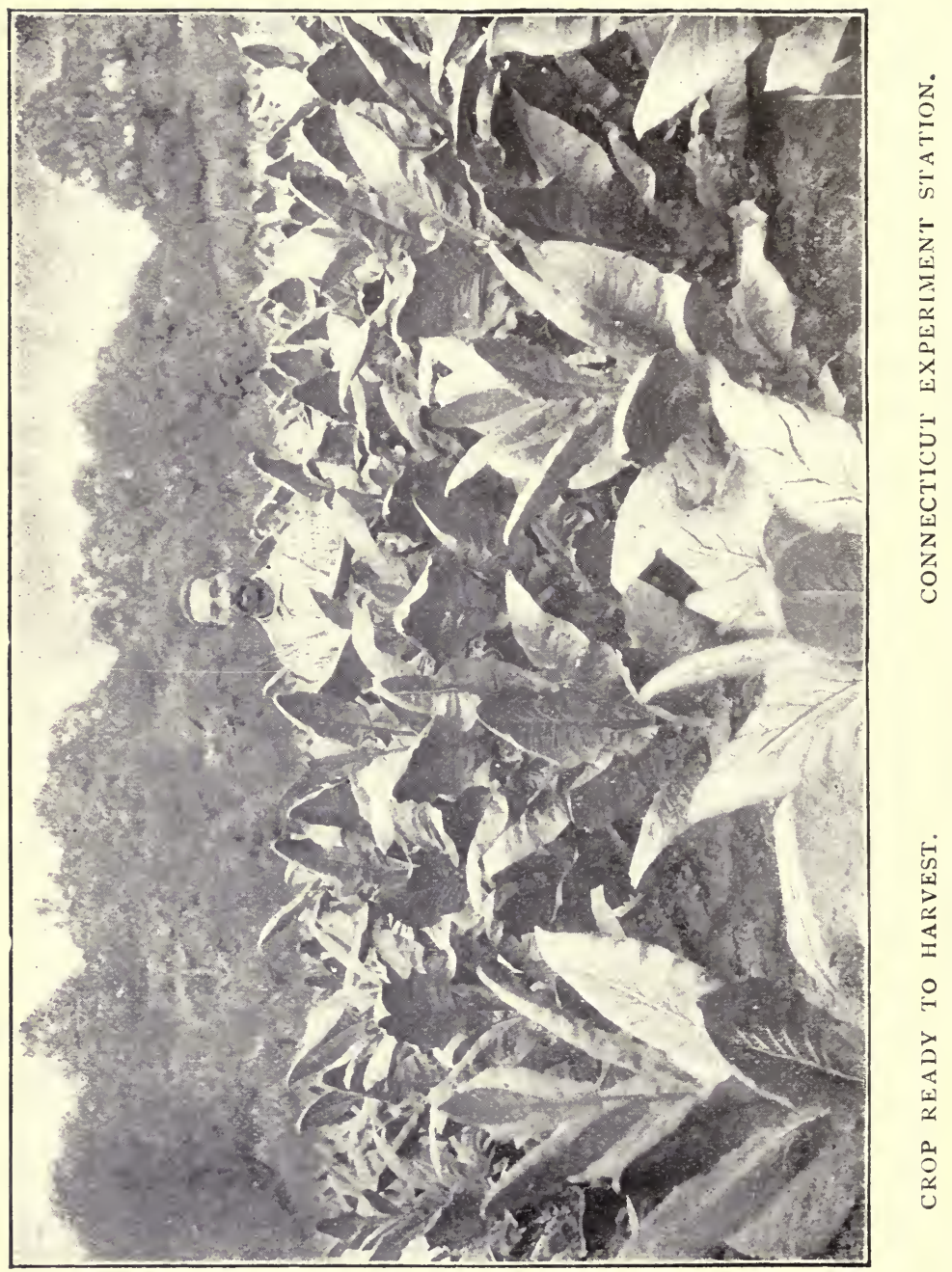


worms. Later cultivation will fill up the furrow, and the plant has thus a better hold on the ground, and will get more moisture than if set in the usual way. The most successful hand tool for making holes for the plant is a narrow piece of board about three inches wide and sharpened. It makes a cut in the soil, not a hole. Then when the plant is inserted into this cut, its roots can be spread out and firmed better than in a round hole.

The Bright Leaf grower follows the Cuban method of fitting his land for the crop after the second plowing, except that he drags his beds flat with a log drag, and places his plants thirty inches apart on these beds. In the Burley region, a flexible slab drag takes the place of the log, and a marker is used for indicating the distance of the rows, and the plants are placed level without either ridges or hilis.

Shipping Tobacco is grown in checks and cultivated both ways. After the second plowing, thorough harrowing follows, and then the marker is run both ways, three and one half feet squares being the result. At the points of crossing, hills are raised by the hoe, a handfui of commercial fertilizer being usually dropped at each of these points, over which is made the hill on which the plant is to stand.

Following the preparation of the land, and its being placed in condition for growing the crop, the application of fertilizer or plant food for growing the crop is the first consideration. The application of fertilizer being a separate and distinct operation, will be discussed in a chapter by itself. 


\section{FERTILIZING.}

In taking up this important branch of the subject, it will be well to give a brief review of the object and value of fertilizing, together with some of the more important facts which seem to influence the field practice of successful growers.

Tobacco is a rank, rapid growing, and heavy-feeding plant, and requires liberal supplies of plant-food. The careful experiments of Dr. Goessman, of the Massachusetts Experiment Station, and of Prof. Stockbridge, of the Florida Experiment Station, furnish information of great practical value to the planter.

As a result of these investigations, the quantities of Phosphoric Acid, Nitrogen and Potash per acre suggested by these two authorities are as follows:

Phosphoric Acid Nitrogen Potash.

Dr. Goesmann

Prof. Stockbridge

Average per acre
$60 \mathrm{lbs}$.

75 lbs.

$6 \%$ lbs. roo lbs. $300 \mathrm{lbs}$. I 80 lbs. $300 \mathrm{lbs}$. I 40 lbs. $300 \mathrm{lbs}$.

The plant food found by chemical analysis in the tobacco plant furnishes a fair guide in determining the kind and amount of fertilizer to use.. Of course, not only the leaf but the whole plant must be accounted for in figuring out the actual plant food taken up. While the leaf is the object of tobacco growing, the leaf cannot be grown without the stalk, roots, etc. The analyses of the whole plant made by Prof. Stockbridge indicate the following plant food re- 
quirements. He found the average Florida tobacco plant to contain:
Phosphoric Acid
Nitrogen
Potash
0.99 per cent.
$2.5^{8}$ per cent.
4.34 per cent.

This indicates that the crop requires its plant food in the proportion of 260 pounds of nitrogen, and 440 pounds of potash for every 100 pounds of phosphoric acid actually taker up by the plant. As phosphoric acid is apt to change in to insolubie forms in the soil, allowance must be made for such losses in making up special fertilizers. Again, many soils accumulate supplies of nitrogen through the growth of legumes in rotation, and a too free supply of nitrogen in the fertilizer may prove very undesirable by inducing a too rank growth of leaf. For these reasons, many experienced tobacco growers use a higher proportion of phosphoric acid, and a lower proportion of nitrogen than the chemical composition of the crop would seem to require.

Prof Stockbridge's recommendation for fertilizer application is based on these conditions, and his formula supplies the necessary plant foods, (as shown by the analyses) which will be removed from an acre of land by a fair crop of tobacco.

Dr. Jenkins, of Connecticut, as the result of his analyses, estimates the quantities of the three essentials removed from the soil by an average Connecticut crop per acre as follows: Phosphoric Acid, I6 lbs.. Nitrogen, Ioo. 1bs.; and Potash I 50 lbs. 
Notwithstanding the material differences in the com. position of tobacco grown in different places, particularly as to the tutal quantities of the different plant-food constituents removed frum an acre of land; all practical planters now agree that the crop requires large amounts of potash as compared with phosphoric acid.

The cunclusions of accepted authorities may be thus stated:- The demands of the crop for phosphoric acid are small, for nitrogen they are large, but the greatest demand is for potash -in fact, greater than that of any other cultivated plant.

The general rule of practice for cigar tobacco planters to follow may be stated thus: Nitrogen, 4 to 6 parts, potash, 8 to 15 parts, and phosphoric acid, I to 3 parts.

This may be more concisely expressed as follows:-

Ammonia

Potash

Available Phosphoric Acid
4 to 5 per cent.

8 to 9 per cent.

2 to 4 per cent.

Commercial fertilizers are valuable as plant food only to the extent that they contain nitrogen, potash and available phosphoric acid, provided always that proper proportions of thesc ingredients are used. An excessive amount of any one of these three plant foods in a fertilizer will not make up for the loss caused by the lack of either of the other. The old saying that "a chain is no stronger than its weakest link" applies here, for, the value of any fertilizerwill depend on the proportions of all three-nitrogen, phosphoric acid and potash which it contains, 
$=-2=-1$

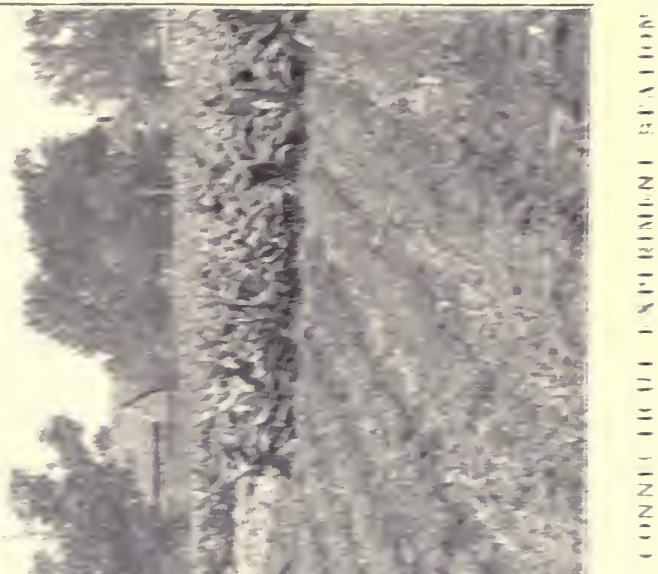

$\vdots$
$\vdots$
$z$
$z$
$z$
$z$
$\vdots$
$z$
$z$
$z$
$z$
$z$
$z$
$z$

$z$
$\vdots$
$\vdots$
$\vdots$
$\vdots$
$z$
$\vdots$
$\vdots$
$z$
$z$
$z$
$z$
$\vdots$
$\vdots$
$\vdots$
$z$
$z$
$z$
$z$ 
The sources from which the different forms of plant bod are obtained is of importance as affecting results. Juriate of Potash and Kainit, on account of the chlorine they contain, will affect ine quality of tobacco leaf unfavorably. High grade Sulphate of Potash should therefore be used as a source of potash, as it is practically free from Chlorine. Sulphuric Acid, a necessary ingredient of Sulphate of Ammonia and Superphosphate, is believed to possess an injurious effect similar to that of chlorine when used in excess. This is an additional reason for discouraging the excessive use of Asid Phosphate, beyond the fact that too much phosphoric acid will not do any good, or in other words, it is just so much money and labor wasted. These disadvantages can be greatly reduced by fall application, and neither phosphoric acid nor potash is as susceptible to very great loss by leaching, as is the case with nitrogenous fertilizers.

The science of tobacco fertilizing is much further advanced in the Connecticut Valley than in any other tobacco district, and there the use of fertilizer is most general, and the yields are for that reason heaviest. The average for Connecticut per acre is 1402 lbs. of leaf as against $373 \mathrm{lbs}$. in North Carolina. (Cigar tobacco is heavier than yellow tobacco.) White Burley and Perique tobaccos are the only classes of leaf largely grown without manure or fertilizers. Rotation, however, is there strictly followed. Tobacco is followed by wheat, which is seeded to Timothy, or bluegrass with clover, and the clover is allowed to remain two or three 
years, before the sod is turned up for a second crop of tobacco. Commercial fertilizers are as yet practically unknown on this crop (the soil being very rich), while barn. yard manure is used only in exceptional cases. In time though, fertilizers will have to be used to return the plant food removed from the soil by even this method of culture of White Burley and Perique tobaccos.

In growing Bright Leaf Tobacco, fertilizing with both barn-yard manure and commercial fertilizers is practised. The manure is generally plowed under at the second plowing. It usually contains large quantities of litter and pine straw, which is believed to aid in yellowing the leaf. The rows are later on laid off by a "scooter" and 600 to rooo lbs. per acre of some standard commercial fertilizer, which shouid contain about 2 per cent Ammonia, 6 per cent Potash and 4 per cent Phosphoric Acid are sowed in the hill, and covered by the turn-plow. The plants are then set on the ridge thus formed.

"Shipping Tobacco" is a product of heavy manuring, heavy soils and slow ripening. All kinds of manures, and large quantities thereof, are used by its growers. These are applied to the land, and turned under in Autumn, as a precaution against "firing" or blasting." Hog manure was once a favorite for manuring tobacco, but the leaf grown on such manure is not of good quality, and is not as highly prized as formerly. Commercial fertilizers are more and more being used, especially on old lands, in conjunction 
with stable manure, as the country develops and the lands become impoverished.

Cigar Tobacco is chiefly produced by the use of commercial fertilizers made specially for tobacco, chemical manures or vegetable by-products. Barn-yard manure, strengthened by chemicals is used somewhat in Pennsylvania, Ohio and Wisconsin. In the Connecticut Vallcy, applications of $3000 \mathrm{lbs}$. of concentrated chemical fertilizers per acre is the rule rather than an exception. Experience shows that better results follow where the nitrugen is supplied in various forms and at several applications; hence it is common to apply nitrate of soda, or dried blood, with cotton seed meal, or castor pomace, as a second application for "working in" after the plants are well started.

The full quantity of phosphoric acid and potash should be applied at one time, and "broadcasted" before planting. The use of high grade fertilizers made expressly to meet the requirements of cigar-leaf is extremely common, and these are generally bascd on the actual needs of the crop as shown by chemical analysis.

The formulas of fertilizers and applications used are numerous. The general aim and practice is, to provide the three essentials in the proportions of about $60 \mathrm{lbs}$ of Phosphoric Acid, 75 lbs. Nitrogen, and 120 lbs. of Potash per acre. This would correspond to an application of $1500 \mathrm{lbs}$. per acre of a fertilizer containing 4 per cent available phosphoric acid, 5 per cent nitrogen, and 8 per cent actual potash. If doubled, this would make about the maximum ap- 
plication used by the best Connecticut Valley.growers, who depend on fertilizers solely for producing tobacco year after year on the same soil.

The Cuban grower of Florida still adheres to his socalled Peruvian, or Damaraland guano. The usual application is from 600 to rooo lbs. per acre. The more progressive growers, however, obtain best results from mixed fertilizers containing 4 to 5 per cent Ammonia, 4 to 5 per cent available phosphoric acid and 9 to 10 per cent potash.

\section{MOST EFFECTIVE APPLICATIONS.}

The following suggestions as to the most economical and productive use of fertilizers are based upon actual practical experience.

Of the three principal food constituents, phosphoric acid is in least demand. It should not be supplied greatly in excess of the actual needs of the plant. The best form is the high grade acid phosphate, and 20 to 60 pounds of available phosphoric acid per acre should be the limit used.

Nitrogen is required by tobacco in proportions of from two to three times the amount of phosphoric acid. Nitrate of Soda and Cotton Seed meal are both popular forms of nitrogen; of the two, nitrate is much quicker in its action.

Potash is the most important plant food for tobacco. This crop is distinctively a potash feeder. The quantity reequired is from four to six times that of phosphoric acid. The best form of potash is the high grade sulphate of potash, containing an average of 50 per cent of actual potash. 


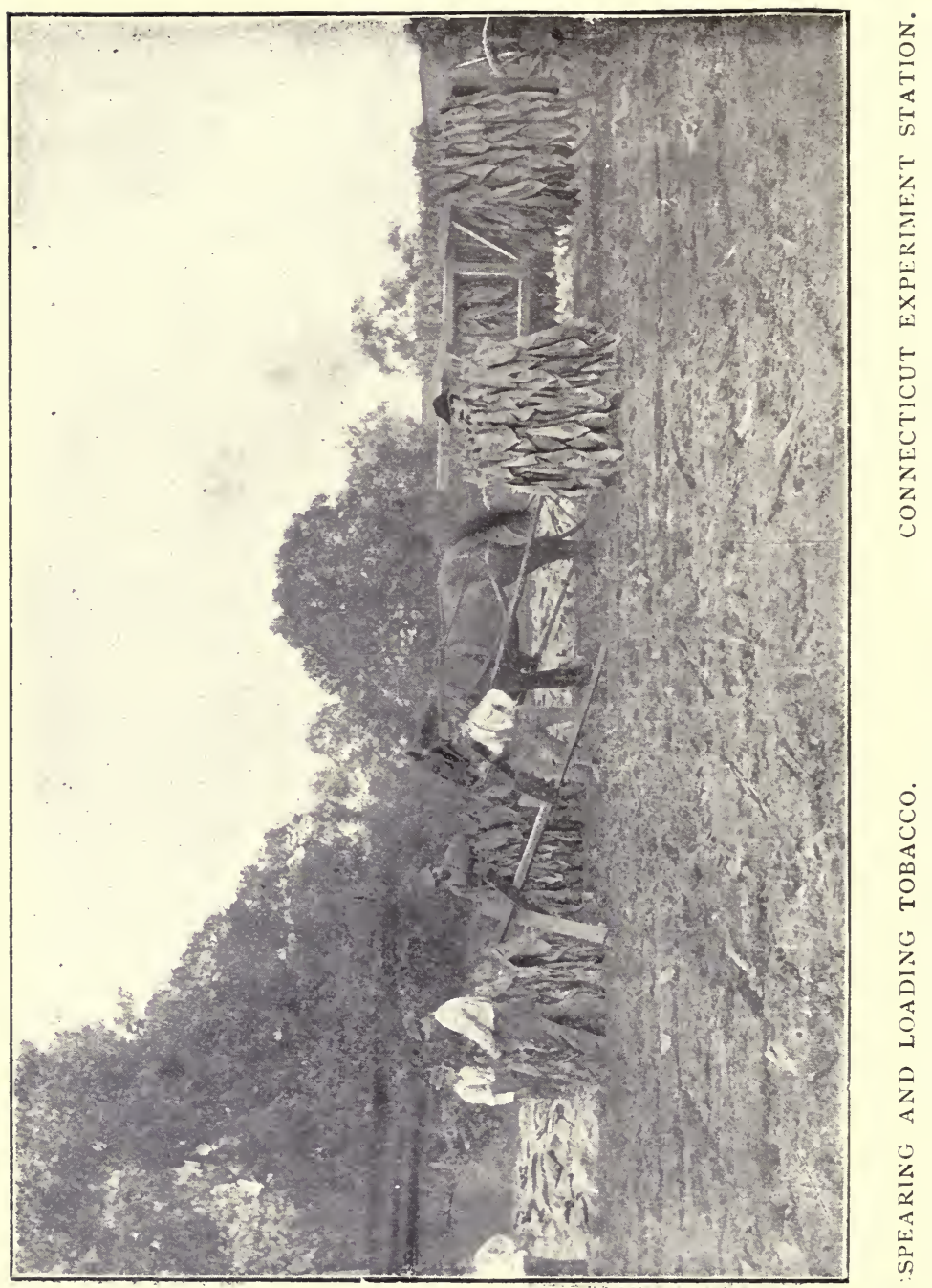


As above mentioned, Muriate of potash or Kainit should not be used on account of the chlorine which they contain.

\section{TRANSPLANTING.}

The soil having been prepared for the growth of tobacco by the incorporation of the fertilizing material, the first step towards the field growth of the crop is, the transfer of the young plants from the seed-bed to the open field. Strong, vigorous plants only should be sclected for transplanting. For a day or two previous to removal, the seedbed should not be watered, in order that the young plants may be somewhat hardened for their transfer to the open grounc. However, just before removal, the portion of the bed from which the plants are to be taken should be thoroughly watered. This is done to moisten the soil so that it will adhere to the roots of the plants removed, forming a ball of earth which will greatly aid a rapid recovery from the shock of transplanting. It is best to remove the plants early in the morning, while they are still moist with dew. The removed plants should be packed closely in boxes or baskets in which condition, if kept covered in the shade, or in a cool place, they may remain for several days withont injury before being set out. Meantime, the plants should under no circumstances be watered or laid in a horizontal position, as such practice leads to injury through heating, or rotting, or "crooking" of the stems of the plant.

The method of transplanting is controlled almost entirelv by the character of tobacco. With all varieties except 
Surratra and Cuban tobacco, when grown expressly for wrapper purposes, requiring very thick planting, transplanting machines should be used. Fully five-sixths of the crop is set out by hand with a peg. Where the plants are to stand nearer than 16 inches in the row, the machine cannot be used and hand planting is unavoidable. The best kind of machine for this purpose, (drawn by two horses and driven by a man) waters the ground previous to the dropping of the plants, two rows at a time being planted; two boys riding upon the machine and dropping the plants as fast as required. For hand planting, cloudy weather, or time just preceding or following showers, should, if possible, be selected.

Hand-transplanting is done by the same method used for other plants, that is, either a peg bluntly sharpened, or the fingers are used for making the hole into which the plant is placed, and the soil is then pressed around the rootlets by a single effort of the peg or fingers. The selection of a particular time is hardly practicable where large acreages are to be planted, though planting late in the day is preferable. However, watering just after setting is usually necessary, and if the planting is followed by hot weather, the tender plants should be shaded.

A very littie water used upon the soil before setting out the plant is much more effective than large quantities applied after the transplanting. An economical and effective method is the running of a furrow along the row into which the water is easily turned, and in the bottom of this wet fur- 
row the plants may be, set with almost certain satisfactory results. Large crops in the south are often transplanted by making a hole with a peg about three inches deep. Into this a half pint of water is poured and then the plant set with the dry soil pressed about the stalk.

The roots of the young plant should not be crowded or cramped by the process of transplanting, but should be spread as naturally as possible. The depth to which the plants should be set is controlled by the variety. Cuban tobacco requires far deeper setting than other kinds. In any case, care must be taken that the bud, or "chit" be left uncovered by the soil.

\section{CULTIVATION.}

Tobacco especially requires clean cultivation and unremitting care. Level culture is preferred with all varieties of tobacco, although in certain sections of the southern states a great deal of tobacco is still grown by the ridge or hili methods. Because of the enormous surface of leaf exposure in the tobacco plant, its water requirements are very great. It is easily damaged by drought. This can be guarded against by repeated shallow cultivation during dry weather By this means, a thin covering of fine earth stops evaporation of soil water. It is, in fact, a mulch. This is particularly important, because the quality of the leaf so largely controls its value. The hill method is adapted to heavy tobacco as the tips of the leaves are somewhat pro tected from the injury which they otherwise suffer by com 
ing in contact with the ground; for the leaves of this tobacco in growing bend downward until they touch the ground.

To secure the finest leaf there should be a steady coninuous growth, without check or set-back by spells of dry weather. It has been found that the use of Sulphate of Potash and Nitrate of Soda as fertilizer ingredients tend to conserve the moisture in the soil.

Worming. The matter of protection against worms and other injurious insects will be discussed further on. Of course, the prime object is to secure a perfect leaf. This is particularly the case of all wrapper varieties, the market value of which is almost ruined by worm-holes. Worming by careful hand-picking is a necessary work, while poisoning of the plants by the use of arsenates, (Paris green, etc.,) is a practice not to be recommended.

\section{TOPPING AND SUCKERING.}

The tobacco plant is forced, in effect, the same as hot house plants. The crop cannot be allowed to make its natural growth, bloom and produce seed, without seriously interfering with the character of the leaf required. "Topping" which results in increased leaf production, or enlarge. ment, is therefore indispensable. Each individual plant must be topped separately by breaking off the flower stem by hand.

There is opportunity for the exercise of much judgment in this process, and strong and thrifty plants require less severe topping than weaker ones. The variety of tobacco, 


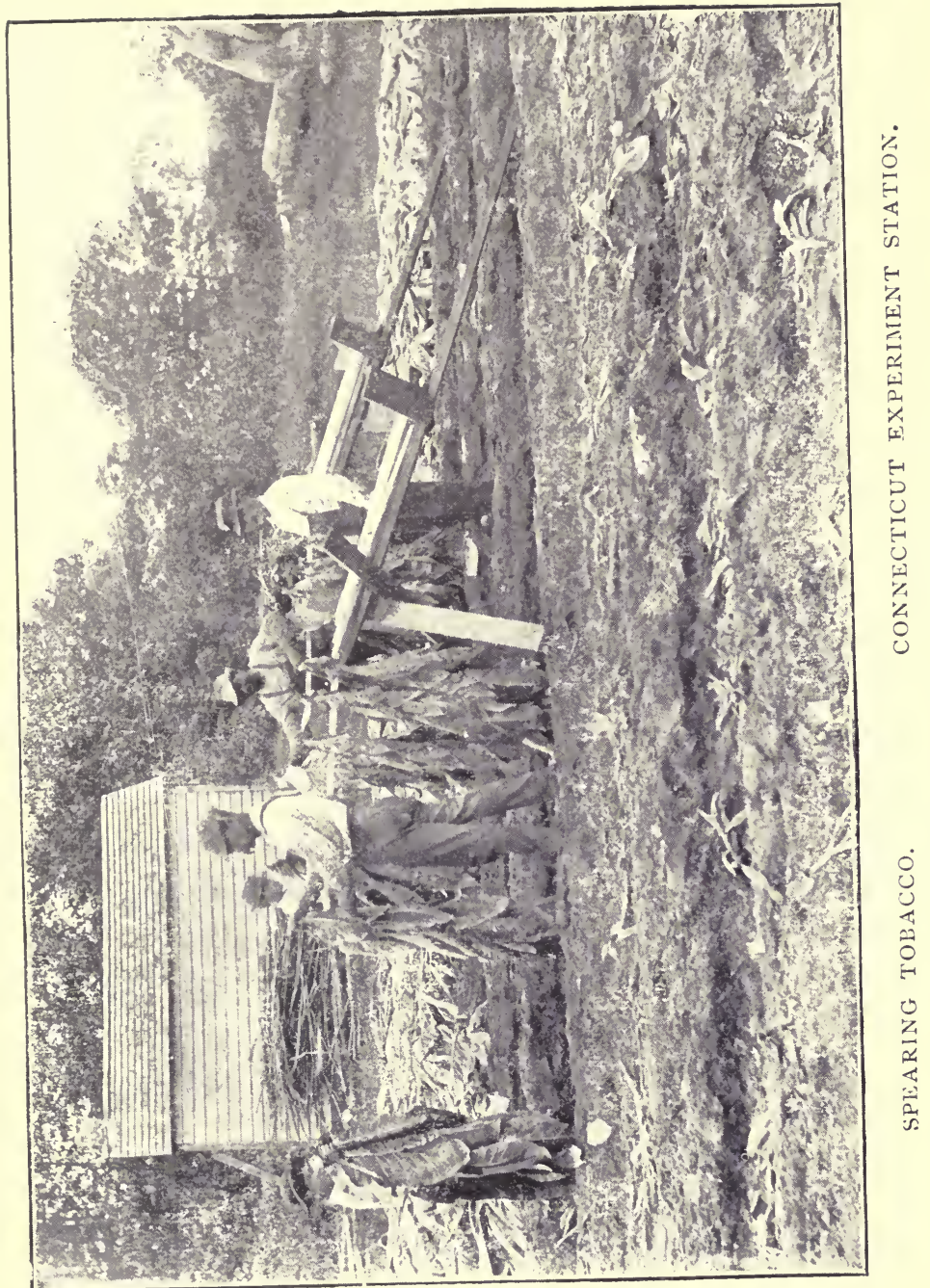


or object for which it is grown will determine the actual amount of topping to be performed. From ten to eighteen leaves should be left to mature, according to the character of the plant, and the kind of tobacco raised. Checking the natural growth of the plant, by removing the flower stalk, results in the pushing out of large numbers of suckers. These must be carefully removed before they attain sufficient size to sap the vitality of the plant, or divert growth from the leaves. "Suckering" is very necessary just before harvesting for, if not removed at this time, suckers will continue to grow during the curing of the plant, and seriously lessen the quality of the crop. Cigar Tobacco is usually suckered twice; heavy shipping tobacco from four to five times. The latter is not harvested as early after topping, as the former.

\section{HARVESTING.}

Tobacco, like all other crops, has a well-defined condition of ripeness, at which time it should be harvested. If delayed too long, deterioration results. A tobacco planter without experience usually has much difficulty in determining the proper stage of ripeness. To an expert, the proper condition is readily detected by a characteristic change in color of the leaf; the dark green appearance is succceded by a lighter shade, which first appears in mottles, or spots, gradually spreading until the entire leaf is involved. A test is often made by pressing a folded leaf between thumb 
and finger, and, if it cracks at the fold, it is a sure indication of ripeness and readiness for harvest.

Cuban tobacco should be harvested in a somewhat greener condition than other varieties. The method of harvesting depends greatly on the kind of tobacco. Sumatra tobacco is more commonly "primed," that is, each individual leaf is examined and picked as it reaches the highest grade possible. They are strung upon strings for curing, and this is done to a large part of the yellow tobacco. Other tobaccos are harvested by cutting the entire plant close to the ground.

The plants are then hung up, by one of several methods, in the curing barn for drying or barn curing. The Cuban grower cuts the entire plant into sections, each having two leaves. These sections of plants are hung, or "straddled" upon single poles which are carried upon the shoulders of two men to the curing barn. By this method the top leaves of the plant must be less mature than older ones. With cigar tobaccos the method of priming, or picking a few lower leaves before the entire plant is to be harvested, is recommended although not in general use.

After the plant is cut, it should be ailowed to wilt thoroughly before further handling. By this means, serious in jury from the breaking off of brittle leaves is avoided. Care must be taken, however, lest the leaves become scorched, or sun-burnt; brief exposure to the direct rays of the sun will do scrious injury.

Most American tobacco is suspended in some manner 
upon slats, laths, or sticks, before being removed to the curing barn. The method most commonly used in the seedleaf districts is that of stringing the plants upon a lath, one end of which is held in a portable "horse," while the other is fitted with a needle, or spear the butt of which is provided with a socket into which the end of the lath is inserted. In the White Burley and Heavy Tobacco districts, the plants are split half-way down, and straddled on sticks.

Bright Leaf Tobacco is cured by artificial heat, and is more commonly straddied on a stick, though frequently the leaves are pulled from the stalk and ticd by twine to the sticks.

White Burley Tobacco is generally allowed to remain suspended from a scaffold in the field two or three days before removal to the barn. The most satisfactory way for hauling the crop from the field to the barn consists of a frame placed upon the bed of a two-horse wagon, so high that the suspended plants do not touch the bottom of the wagon, and so wide that the ends of the lath rest upon the side pieces of the frame. By this means space is saved, and the robacco has very much the same position as when it hangs in the barn, and little injury is done by the hauling.

\section{HOW TO BUILD FRAME AND LOG CURING BARNS.}

After the curing of Bright tobacco, the most important aing is that the curing barn should be well built. The planter may raise fine tobacco crops, but without good 
barns, he runs a great risk in curing them. The frame barn is more expensive to build than the log, but it gives better satisfaction.

A good size for the building is $16 \times 16$, or $16 \times 20$ feet inside measure. i 8 feet from the ground to the plate, with brick foundation $2 \frac{1}{2}$ to 3 feet high. The bricks can be turned the nine inch way, which greatly economizes material and answers every purpose. The pillars at each corner must be built strong. The building is an ordinary frame structure, weatherboarded, with studding iz inches apart from center to center; manila paper being on studding on the inside, and ceiling half an inch thick and 8 inches wide, is nailed on the top of this. The roof is sheathed and shingled in the ordinary way, with an opening 6 inches wide left under the comb the entire length. A board fastened with hinges is arranged to open and shut over this place at will. Ventilation is given from the bottom. The tier poles are made of $3 \mathrm{x}_{4}$ scantlings, fastened securely to the side of the building, the first set being 7 feet from the floor, and forty-five inches apart from center to center. The next set must be directly above and 18 or 20 inches higher, and so on till the body and roof of the barn are filled in like manner. The space between weather-buarding and ceiling can be filled in with sawdust, in addition to the paper.

A curing barn, if built of good material, will last for years. It is an absolute fact that tobacco cured in the frame building has a sweeter flavor than that cured in the oldfashioned log barn The difference is accounted for in this 


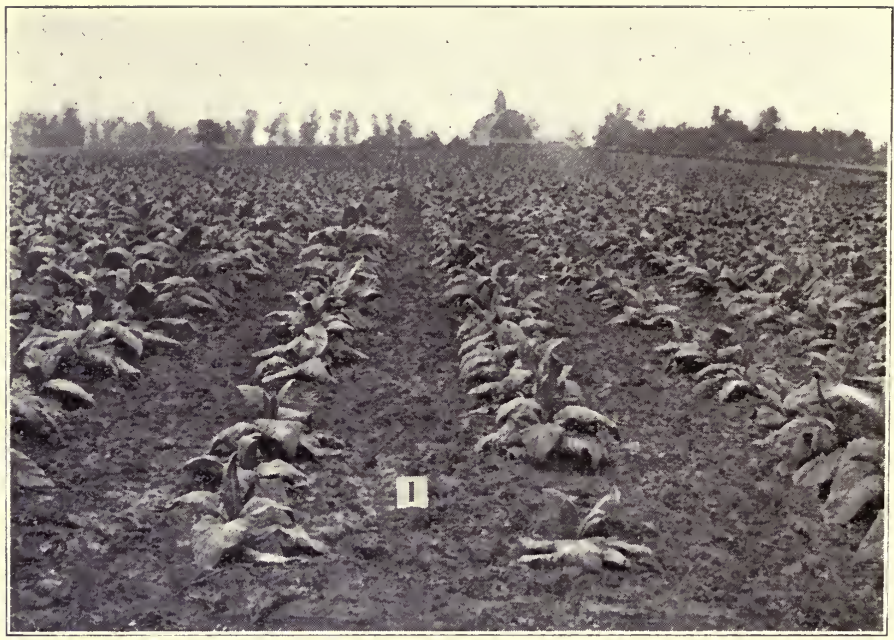

NOT FERTII.IZED.

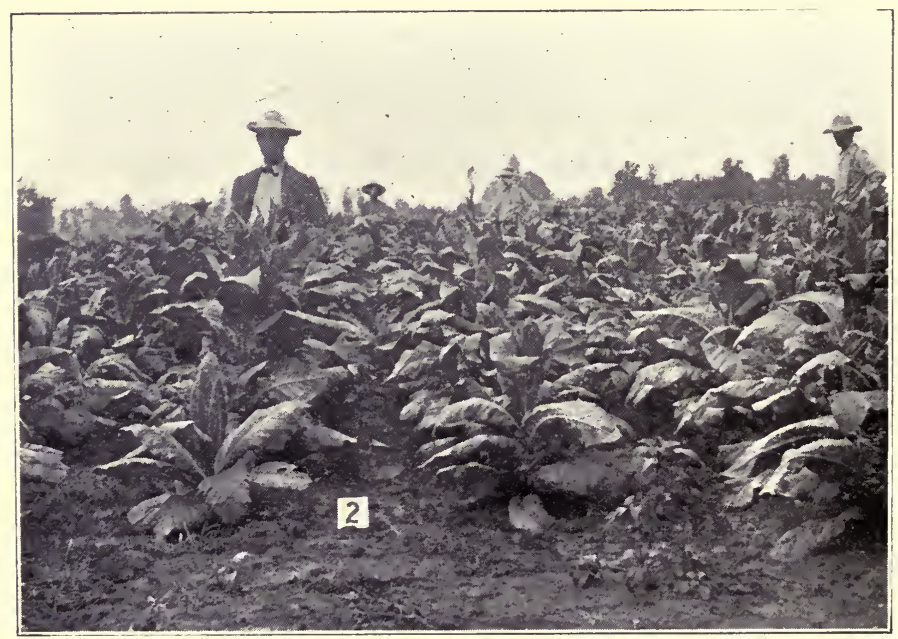

FERTILIZED WI'I 3\% NITROGEN, 8\% PHOS. ACID, IO\% POTASH.

Plot. Treatment.

rields (leaf.

Value.

No. I. No Fertilizer.......................... II 52 lbs. (a I 2 cts....... \$1 38.24 .

No. 2. Potash, Phosphoric Acid and Nitrogen....... 1458 lbs. @ r6 cts....... 233.28.

No. 3. Phosphoric Acid, Nitrogen (No Potash)....... 1320 lbs. @ 15 cts....... 198..

Value of increase due to POTASH \$35.28. 
way: In the process of curing, the leaf attracts the moist. ure from the mud and logs while it is in the drying state. This fact is especially noticeable, and the flavor more impaired, during damp weather. The ordinary brick furnace and I I inch flue furnish the heat in both barns.

Farmers who cannot afford to build frame barns at the start will find the following directions for the erection of log barns useful: The best size is $16 \times 16$ feet inside, and 16 feet from the ground to the plate. Cut poles about the size of those used in an ordinary log building, and 18 feet in length. Remove the bark from them. Place blocks at each corner 12 inches high. Put the poles in position, and notch them into each corner, till the building measures I 5 feet high from the ground to the plate. In carpenter's parlance, put on a "square roof" covering it with shingles or boards, leaving an opening 6 inches wide under the comb the entire length of the building. Fit a 12 inch board over this space, and fasten it to the comb with hinges, so that it can be opened and shut as desired. The poles commence 7 feet from center to center, the next set comes in directly above, 18 to 22 inches higher, and so on t.ll body and roof of the building are filled in. Fill in the open space under the sills with logs. Make the building tight by daubing inside and out with clay or lime mortar. The heat of curing is furnished by a brick furnace and flues. Over the door end there should be a shed I 2 feet wide to protect the tobacco from the sun while it is being strung, and at the furnace end, one 5 or 8 feet wide. Those who are building frame 
barns will please note that sheds front and rear as described with this building, are necessary.

\section{BARN CURING.}

Two methods of barn curing are practiced for most varieties of tobacco. These are: (I) natural curing, and (2) fire curing. As a rule, the latter method is followed only with Bright tobacco, and heavy shipping tobacco, while the natural method is that commonly used with other varicties. However, artificial heat is generally recommended, and it is used by successful growers especially for cigar tobacco.

By either method, slow drying during the first, or "yellowing" stage is important. After this yellowing, the more rapid the drying, especially with yellow tobacco, the better. In curing heavy shipping tobacco, the practice now is to keep up only heat enough to prevent house-burning or pole sweating. The fires are often drawn so that the leaves may come in case, or be pliant.

The barns should be as nearly air-tight as possible. They should be provided with thorough ventilation and convenient means for controlling the same. Ventilators in the ridge pole, which may be operated by pulleys from the ground, are very desirable. Horizontal ventilation, or ventilating shutters in the sides of the barn, is more desirable than the usual vertical openings. Tight construction of the barn, and provision for ample ventilation, easily contrelled give results that are usually better than where the ventila. tion is more or less a matter of guess work. 


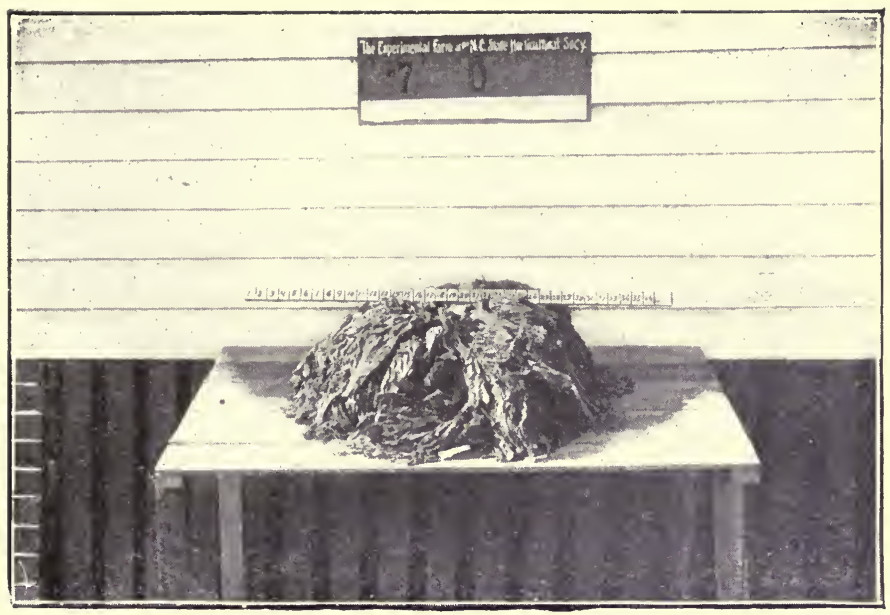

TOBACCO UNFERTILIZED. EXPERIMENT FARM, NORTH CAROLINA STATE HORTICULTURAL SUCIETY, SOUTHERN PINES, N. C.

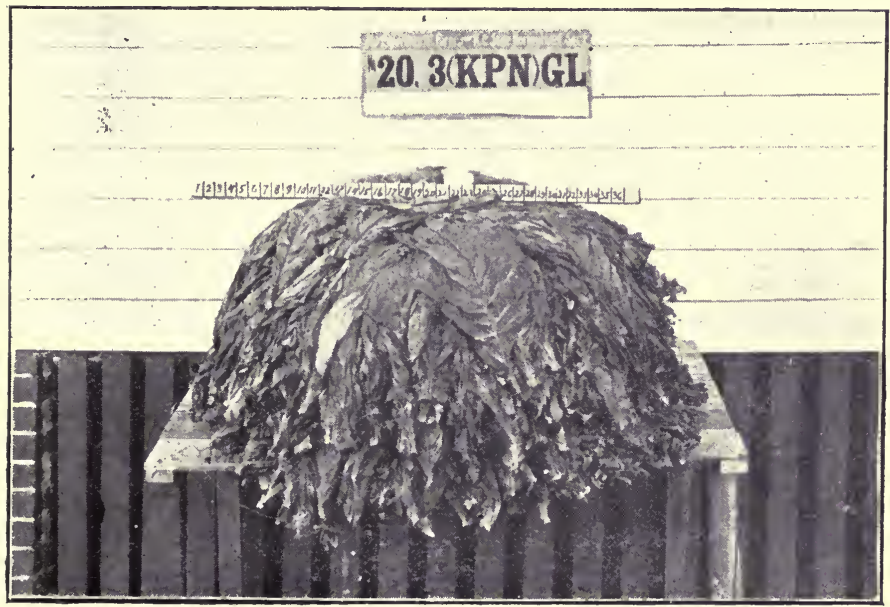

TOBACCO WITH COMPLETE FERTILIZER. EXPERIMENT FARM, NORTH CAROLINA STATE HORTICULTURAL SOCIETY, SOUTHERN PINES, N. C. 
Extreme care during the first few days of the curing process is necessary, lest with hot, dry weather the process proceed too rapidly. If such conditions exist, ventilators should be kept closed during most of the day, but be open at night, as by this means, slower, early-curing is secured. After the "lemon condition" has been evenly secured, drying should be hastened. Tobacco in the barn should not be crowded until the stalks and midribs are well cured.

\section{FORMULA FOR CURING BRIGHT TOBACCO BY ARTIFICIAL HEAT.}

No one can advise another just exactly how to run the heat, or how to cure tobacco, unless he be there in person throughout the time of curing. There is a wide differenre in the kinds of tobacco, some yellow, some green, some ripe, some light bright, some heavy, some thin and smooth, some thick and coarse. The careful or expert curer is governed by the condition of the tobacco itself. Too much heat in drying the leaf will scald or scorch it through and through, while not enough heat will redden the leaf on the inside. While drying it is better to run the heat as fast as possible, short of scalding or scorching the leaf.

As soon as barns are filled with tobacco from the fields before retiring at night, build fires in the flues and run the heat to 90 degrees Fahrenheit, but make sure that the heat will not exceed 9o. By morning, the barn will be about cooled off. Then build fires sufficient to run the heat up to 
90 degrees again, and you can work at something else for the day. At night build fires again to 90 degrecs, and keep running the heat to 90 degrees each night and morning until the tobacco is yellow three or four inches up the leaves from the tips. Then run the heat up to r ro ; let it stay at I ro degrees for one hour with doors and bottom ventilators open, then raise the heat to $\mathrm{x} 20$ till the leaf is cured one-third its length on the bottom tier, raise to $\mathrm{I} 30$ degrees, and stay at $\mathbf{z} 30$ until the bottom tier is cured, a dvance the heat to 140 and keep it at $\mathrm{I} 40$ for five hours. Then raise the heat to $\mathrm{r} 60$ degrees and have it remain at $\mathrm{r} 60$ till the leaf is cured in the top of the barn; advance to 180 degrees and stay at 180 till the stems are about all cured; then raise heat to 200 degrees for 20 minutes; then let the heat down to 180 degrecs, and if the stcms in the corner of barn are thoroughly cured, stop firing and let the barn cool off; the work is donc.

Yellow the tobacco with closed doors; open the doors at I I degrees, and keep them open until you reach i6o degrees, then close the doors; close bottom ventilators at 180. The reason for letting the heat up and down while yellowing, is that the tobacco has time to dry and will stand the heat in drying better, and does not begin to dry before it is yellow.

Some claim that it is not best to carry the heat to over I 80 degrees, but experience shows that if the heat is run to 200 degrees for 15 or 20 minutes, it takes out all the green taste and smell and the tobacco will keep sound and sweet and may be packed down better than when cured with less 


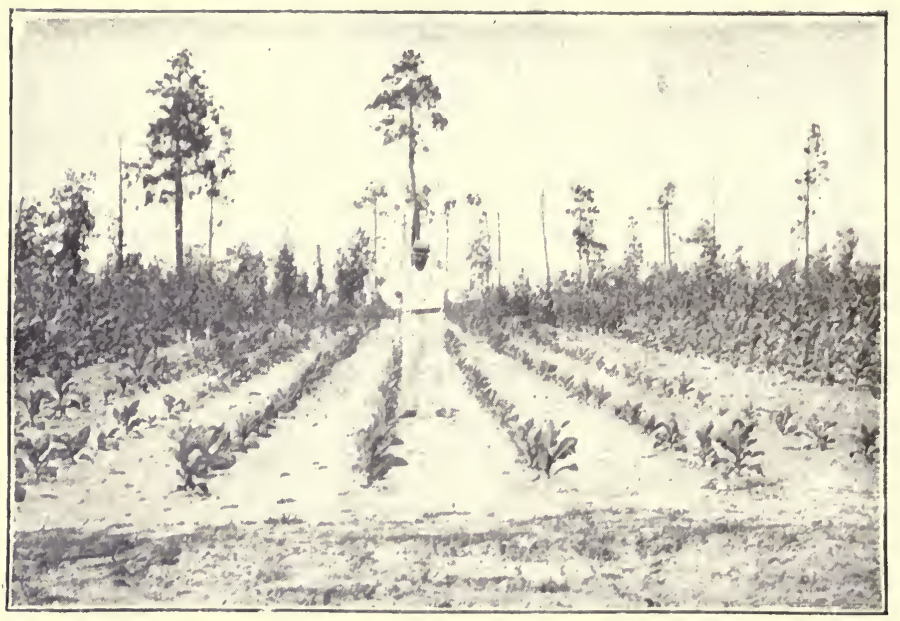

TOBACCO UNFERTILIZFI, EXPERIMFNT FARM, NORTIL CAROIINA STATE HORTICULTURAL, SOCIETY, SOUTHERN PINES, N. C.

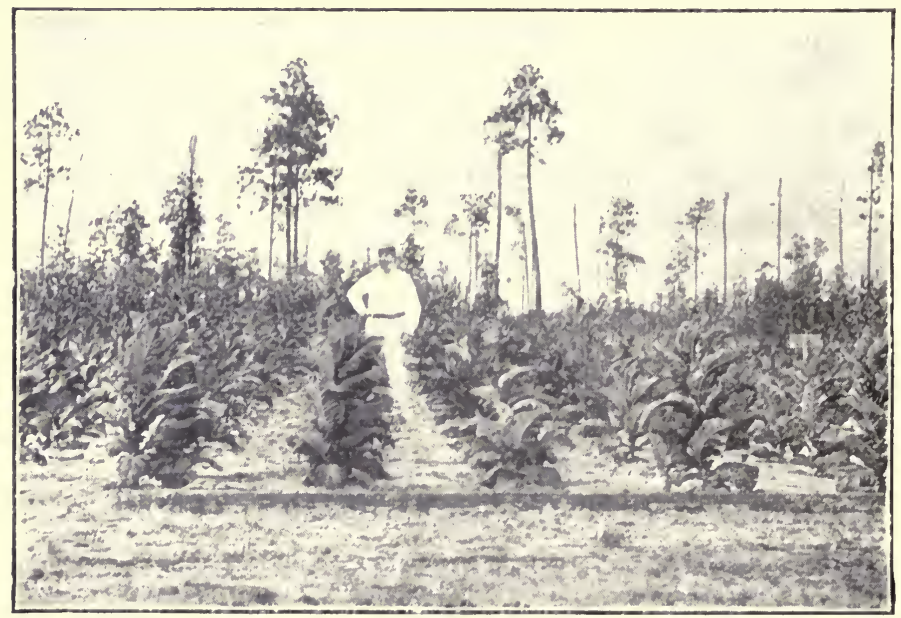

TOBACCO FERTILIZED. EXPERIMENT FARM. NORTH CAROLINA STATE IIORTICUITURAL, SOCIETY, SUUTIIERN IINES, N. C. 
heat. Nothing succeeds like success, and if you know how to dry tobacco well, you will be successful. Be careful not to scorch it.

No general flue-curing system is yet arlopted for other than the Bright tobacco. The two things to sece about are that fires are maintained in stoves or furnaces outside of the: curing room proper, and that the heat is properly conducted through the lower part of the barn by return flues or smoke pipes. The heat naturally rising to the upper portion of the barn, affects all portions alike. Open fires only are employed in the heavy shipping districts. The creosotic compounds deprosited on the leaves by smoke impart a flavor which is highly regarded by European consumers.

\section{MARKETING.}

The sweating, fermenting or finishing of the leaf is a manufacturing process, and does not naturally belong to the province of the grower, whose crop must be marketed in a barn-cured condition. In most tobacco districts, except those particularly devoted to cigar leaf, the warehouse systern of marketing, which is practically the same as that practiced with the cotton crop, is in vogue. Cigar tofjaccos are packed in boxes, yellow tobacco in tierces, heavy tur,accos in hogsheads.

Cigar tobacco is generally sold either green in the field or while still hanging in the curing barn. But such practice opens the way to serious misunderstandings between buyer 
and seller, so that it should only be followed where binding written contracts, covering all details, can be made.

The value of tobacco is largely a question of personal judgment. There are no actual stindard grades like those recognized in the wheat and cotton trudes, and therefore every grower should post himself thoroughly on the actual demands of the market for the kind of tobacco zehich he produces, and especially as to the effects of different methods of growing and fertilizing upon the quality of the leaf.

\section{INSECT ENEMIES.}

Tobacco is attacked by a considerable number of insect pests. The number is perhaps not greater than that preying upon other farm crops, but their depredations may be far more serious, owing to the fact that the value of the growth depends so largely upon the perfection and appearrance of the leaf, which insects prey upon.

Flea Beetles. This pest chiefly attacks the young tobacco plant during its first stage of growth. Two different species of these beetles are recognized; the first is black in color with the exception of feet and antennae; the second is longer, but otherwise about the same size and of a dull black color, except that its feet, antennae, and under part of the body are light yellow. The injury is done through sucking of the juices of the plant, and being a sucking insect, poison is of little avail against it. The surest protection is the covering of the beds with cloth as described, although 


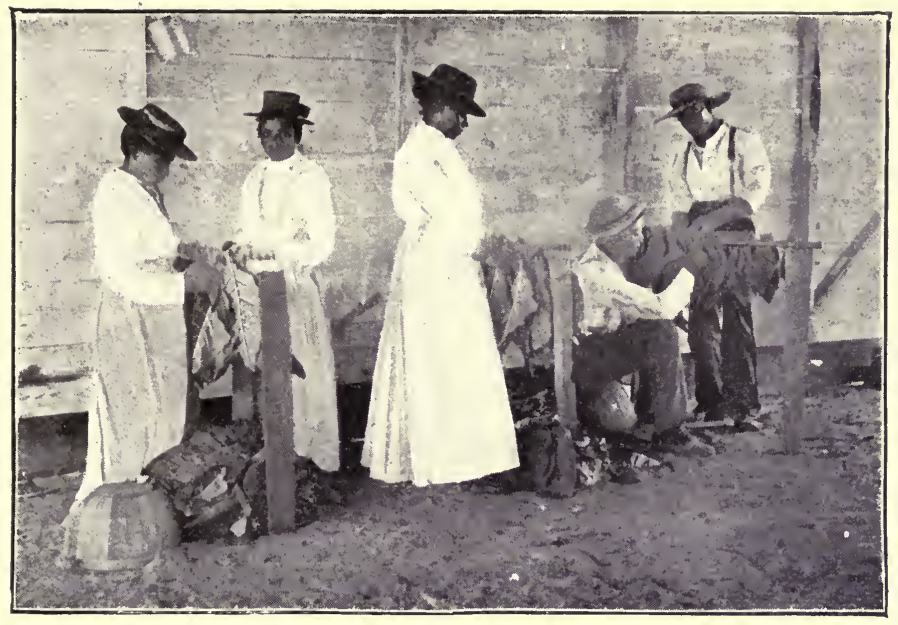

PREPARING TOBACCO FOR CURING. EXPERIMENT FARM, NORTH CAROLINA STATE HORTICULTURAL SOCJETY, SOUTHERN PINES, N. C.

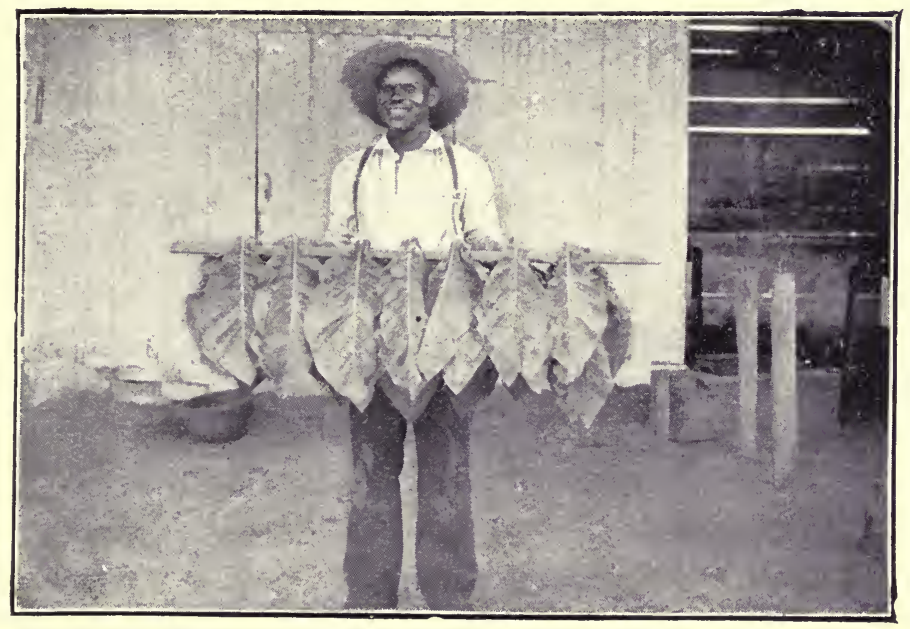

TOBACCO READY FOR CURING. EXPERIMENT FARM, NORTH CAROLINA STÂTE HORTICULTURAL SOCIETY, SOUTHERN PINES, N. C. 
sprinkling the plants with land plaster, fine wood ashes, or dust is somewhat effective.

Cut-Worm. These pests are most injurious to the newly set out plants. They cut through the stem of the plant just at the surface of the soil, their depredations being committed almost entirely at night. They hide beneath the surface of the soil, as soon as daylight arrives; but their love of shelter and darkness may be made their ruin. A scattering of small boards, shingles, or even armfuls of cut grass through the field, attracts them as shelter, beneath which they can readily be found in the morning and destroyed. The poisoning of green grass by a mixture of Paris green and bran may be used, if handfulls of the mixture be scattered between the rows. But really the best protection against this pest is in the line of prevention, which may be secured by clean culture and the burning of all litter and useless vegetable growths in the fall, so that their winter hybernating places are destroyed

\section{GREEN HORNWORM.}

This is a distinctive tobacco worm. The only sure protection is by hand picking and destruction. When the pest becomes prevalent, this must be vigorously followed day by day, as its depredations upon the leaf result in the eating of large holes, and it may end in utterly ruining the crop so far as successful wrapper tobacco is concerned. The moth which lays the eggs for the worm may be trapped by exposing the blossoms of common jimson into which has been 
dropped a mixture of cobalt and honey. It is quite necessary that the tobacco be thoroughly hand wormed just previous to harvesting. Otherwise, the worms will be conveyed to the barn, where their depredations continue so long as the tobacco remains green. A few toads hatbored and protected in the tobacco barn will destroy many of the worms which have escaped from the field to the barn in this way. The green worm, as well as grasshoppers, crickets, and other pests living on the growing leaves, may be destroyed by the use of Paris green, either in dry mixture, or in water by sprinkling or spraying the crop in the same way that protection is secured against the ravages of the potato bug.

\section{DISEASES OF TOBACCO.}

This crop is not subject to many serious diseases, yet a few require mention.

Rust or Fire Blight is the most common disease of the growing plant. This disease is one which the grower can control, by aroiding the use of too large a quantity of vegetable manure, the heating or decomposition of which, if followed by dry weather, has an injurious influence upon the crop. Havana tobacco is very subject to this trouble, especially during the hot rainy weather of August. A good preventive is a heavy mulching of the soil after the last cultivation. Fine straw makes an excellent mulch, and is easily raked up and applied. Wherever used in sufficient bulk it always proves a success.

Spotted Leaf, or, as it is commonly called, Calico Leaf, 


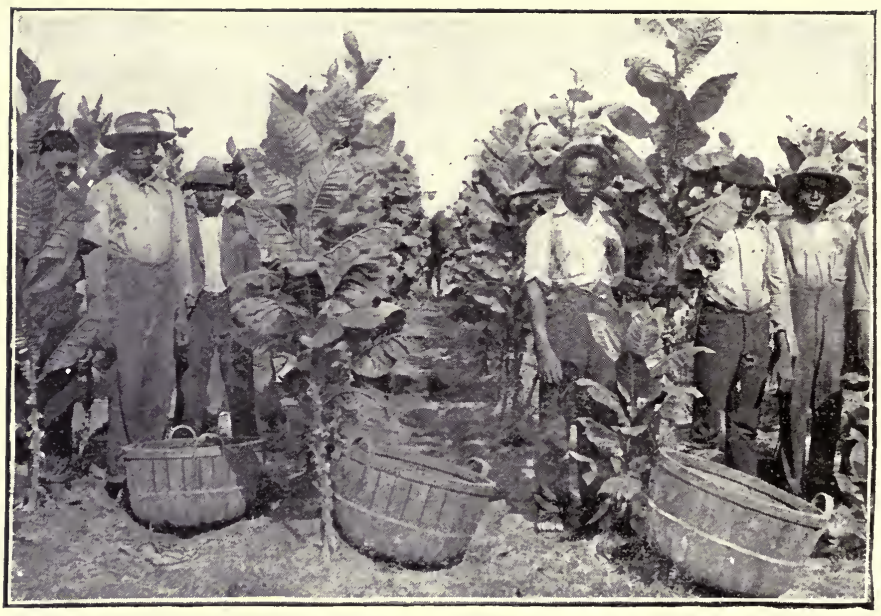

TOBACCO FIELD NEAR WINSTON, IN. C。 
is more or less prevalerit, and is due to the presence of a fungus, against which no protection has yet been found.

Frenching is a more or less serious disease in many localities being particularly prevalent upon clay or badly drained lands. It is far more common in wet than in dry seasons. It shows itself in the buds of the plants, which become a sickly yellow; and the leaves instead of attaining a natural growth develop long, thick, fleshy growths, wholly unlike the normal leaf, often being simply long, narrow masses of foliage, possessing almost no resemblance to the typical foliage of the plant. Such tobacco is absolutely worthless. For the disease, no remedy can be suggested, although thorough drainage of lands where it has appeared is a preventive measure.

The most important disease of the curing leaf is Pole sweat or House-burn. This is the product of bacterial infection or partial decomposition of the tissues of the leaf, superinduced by hot murky weather, or too close packing in the barn. Rapid drying is a protective measure. The discase results in change of the color of the leaf from the natural greenish yellow to a deep brown, and the whole leaf becomes transformed from its natural fine textured condition to a soggy mass without elasticity or strength. No cure has been suggested, but thorough ventilation of the curing barn, and the use of artificial heat for rapid drying after the first stage is past, are the most practical means of prevention.

Stem Rot attacks the leaf in the later stage of curing and shows itself in the presence of whitish patches of mold upon 
the stalk and rib. This is a fungous growth against which no cure can be suggested, but the nature of the infection itself suggests an effec:ive remedy. Absolute cleanliness in the curing barn, and the annual destruction of all refuse from the previous crop furnishes reasonably certain protection by destroying any spores of the disease existing in the previous crop. 


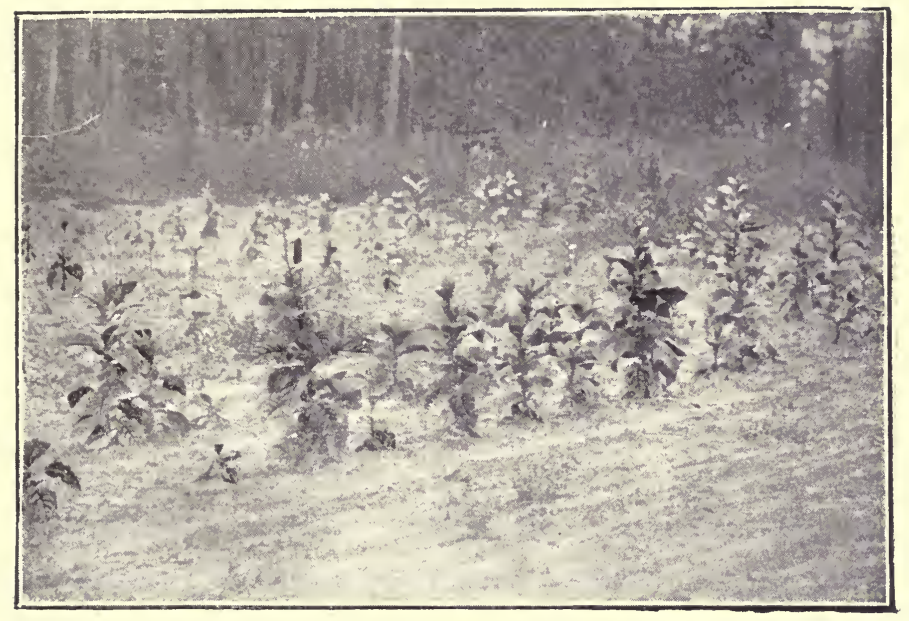

TOBACCO UNFERTILIZED.

ON FARM OF C. K. MCQUARRIE, DE FUNIAK SPRINGS, FLA.

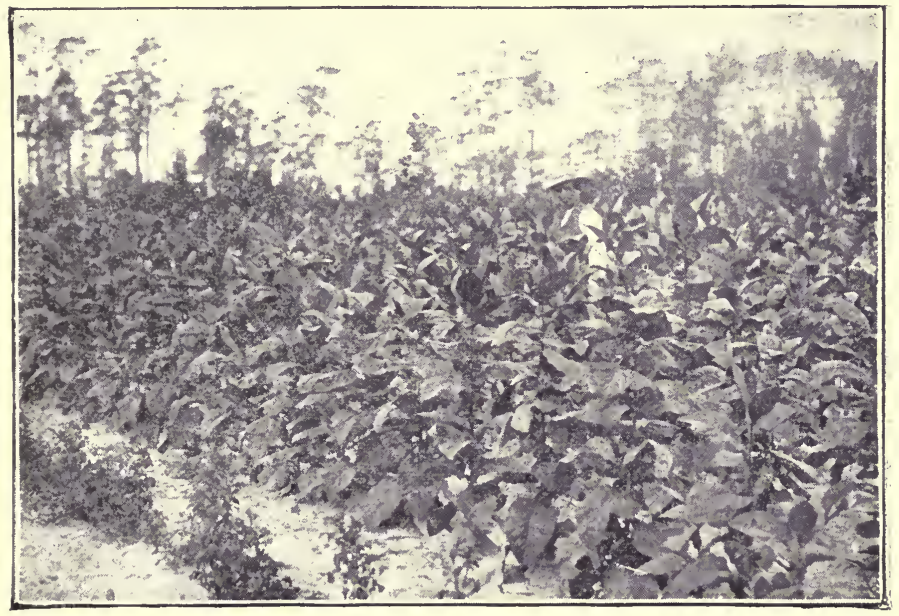

TOBACCO FERTILIZED.

ON FARM OF C. K. MCQUARRIE, DE FUNIAK SPRINGS, FLA, 


\section{APPENDIX.}

\section{DESCRIPTION OF FERTILIZER MATERIALS.}

Broadly speaking, there are two kinds of fertilizers; those which are in themselves a direct source of plant food, and those which by their action tend to make plant food fertilizers more available. While crops may be grown without the use of fertilizers of the second class, no crops can live without the fertilizers of the first class, even though ample applications be made of the former.

Fertilizers of the second class comprise lime, gypsum, and common salt. They are all useful, but rarely indispensable. Lime, gypsum, (plaster), and common salt are sometimes called "stimulant fertilizers." They tend to make rapidly available the stores of ammonia, putash and phosphoric acid naturally present in the soil. When stimulant fertilizers are $u=e d$ exclusively for a term of years, the soil each year loses ammonia, potash and phosphoric acid, which are not replaced. The inevitable result of such treatment must naturally be the exhaustion of these important food constituents from the soil.

True fertilizers contain forms of plant food, which contribute directly to the growth and substance of plants. Such materials may contain either ammonia or potash, or 
phosphoric acid compounds, or any two, or all three of these forms of plant food. The tables given at the end of this chapter show the composition of the most commonly used fertilizers.

Nitrate of Soda, known as "Chili saltpetre," is found in large deposits which have been formed in the rainless regions of Chili and Peru.

Sulphate of Ammonia is formed from waste materials produced in the manufacture of illuminating gas or coke.

Whole Cotton Seed. Whole cotton seed is rather slow in becoming available as fertilizer. By rotting to "kill" the seed it is made more effective. The common practice is to pile in large heaps and leave standing for several months. This not only kills the seed, but also prevents the injurious action sometimes observed from using raw seed as manure.

Cotton Seed Meal is the product formed by removing the oil from cotton seed by pressure, after which the material is dried and ground. The hulls of the cotton seed also possess considerable fertilizing value.

Tobacco Stems are the refuse from $t$ obacco factories.

Dried Blood consists of blood obtained from slaughtering animals; it is prepared for market by coagulating, drying and grinding. The color varies from red to black.

Dried Fish Scrap, consists of the meat and bone of fish after the oil has been pressed out, it is dried artificially and ground for market.

Meat Scraps or Tankage, etc., are slaughter-house refuse, dried and ground. 
Nitrogenous Guanos are formed in dry regions. The Peruvian guano is rich in ammonia, containing 8 per cent. or more. They usually contain 7 to 22 per cent. phosphoric acid, and about i per cent. potash.

Bones consist mostly of phosphate of lime, which constitutes from one-half to three-fifths of the weight of the bone. The remaining portion is a soft, fleshlike substance commonly called gelatin. It is distributed throughout the entire mass of bone, and is rich in nitrogen. When bones are burned, the nitrogenous matter is driven off and only the mineral portion of phosphate of lime remains. Bones, such as are used in making commercial fertilizers, contain 5 to 6 per cent. of ammonia, and from 20 to 25 per cent. of phosphoric acid, about two-thirds of which is insoluble and approximately one-third available.

Bone Products. All forms of bone products are valuable fertilizers, as they supply phosphoric acid, and generally ammonia also. The most common forms are bone black, bone meal and bone tankage. Bone-black is a byproduct of sugar refining, and contains from 30 to 35 per cent. phosphoric acid, more than half of which is immediately available. Bone meal is simply ground bones, steamed or raw. It contains 3 to 6 per cent. of ammonia and 20 to 25 per cent. of phosphoric acid. Bone tankage is a very irregular product, but follows bone meal closely in composition. It is a by-product of the smaller packing houses.

Phosphate rock. This is a mineral phosphate, found in various States. In a raw condition it contains from 25 to. 
35 per cent. phosphoric acid, all of which is insoluble and not available for plant food. The mineral has to be treated with sulphuric acid, before the phosphoric acid can be liberated.

Acid Phosphates are known under several different names, such as superphosphates, dissolved bone, dissolved rock, dissolved bone-black, etc. Acid phosphates are formed by treating some form of insoluble phosphate of lime, as rock-phosphate, bone, bone-ash, etc., with sulphuric acid. By this treatment there are formed soluble phosphates of lime and gypsum (sulphate of lime) in nearly equal proportions.

Cotton Seed Hull Ashes were produced in the South at the cotton seed oil factories, where the hulls, after being removed from the cotton sced, were used as fuel. This material is not commonly found now.

Kainit is the most common product of the German potash mines. It is a mixture of several different compounds, containing 12 to 13 per cent. of actual potash, together with about 35 per cent. of common salt, also magnesia salts.

Muriate of Potash also a product of the Stassfurt mines, is the main source of supply for potash for commercial fertilizers in our market, and contains from 50 to 53 per cent. of actual potash.

Sulphate of Potash is a product of the German mines. The product found in the market contains from 48 to 5 I per cent. of actual potash. 


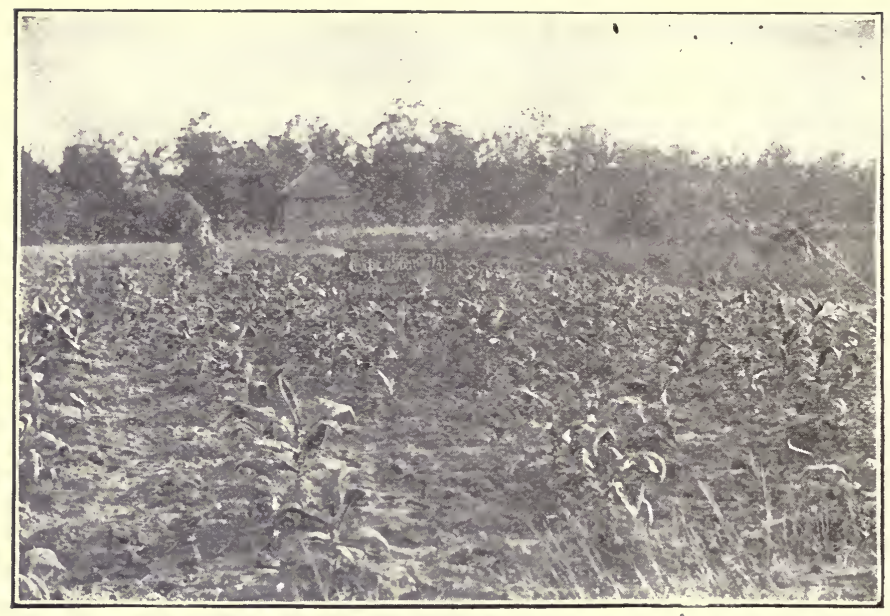

TOBACCO UNFERTHLI'EL.

ON FARM OF T. B. LINDSAY, DOUGLAS, N. C.

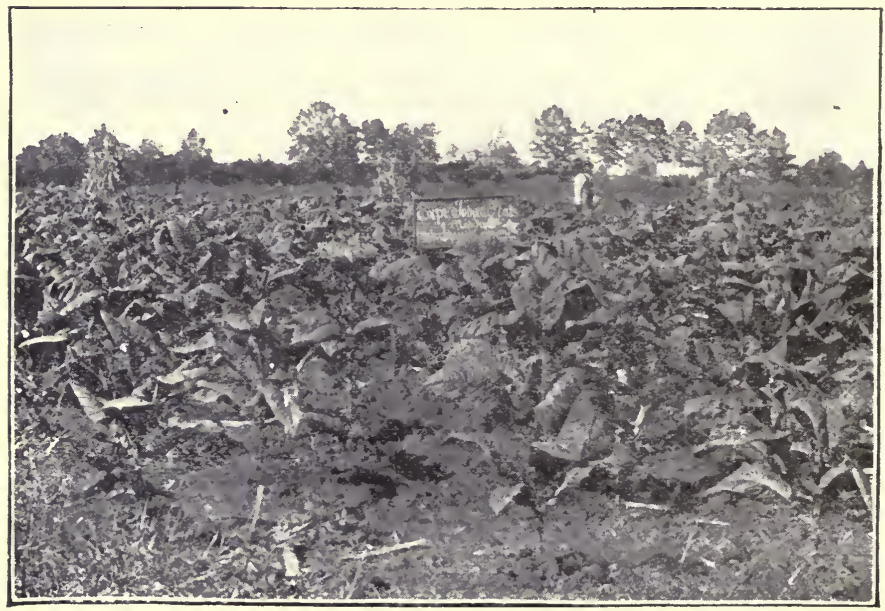

TOBACCO FERTILIZED.

ON FARM OF T. B. LINDSAY, DOUGLAS, N. C. 


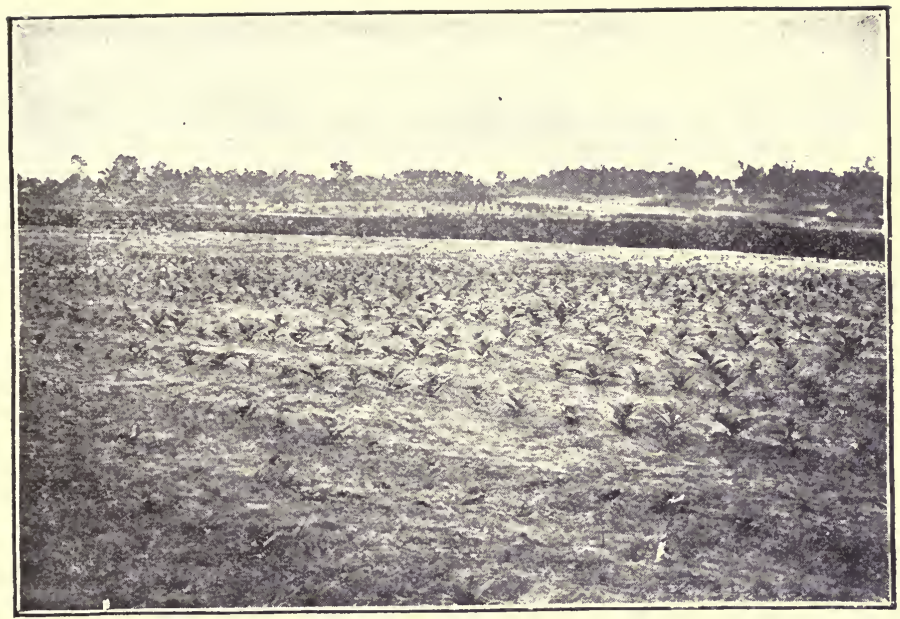

CUBAN TOBACCO ON NEW GROUND. FLORIDA EXPERIMENT STATION.

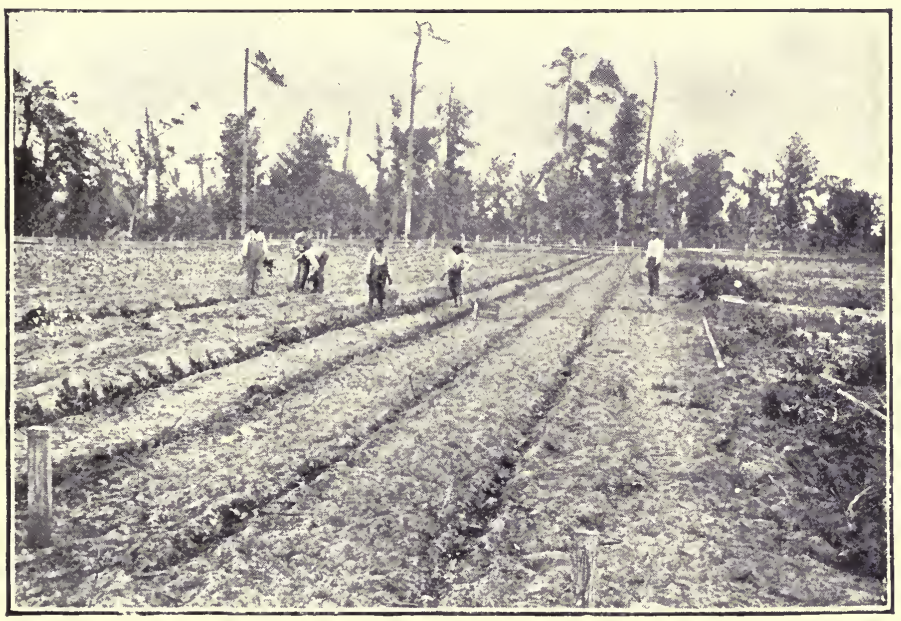

TCRACCO ON NEW GROUND. SHADING TRANSPLANTED PLANTS. FLORIDA EXPERIMENT STATION. 
Manure Salt is another product of the Stassfurt mines and contains a minimum of 20 per cent. actual potash.

Sulphate of Potash=Magnesia is known also as Double Manure Salt, or low grade sulphate of potash. This material comes from the German inines and contains 26 to $2 \&$ per cent of actual potash. It also contains $3^{2}$ to $3^{6}$ per cent. of sulphate of magnesia.

Carbonate ( $\mathbf{f}$ Potash= Magnesia contains about i 8 per cent. potash and 19 per cent. magnesia, both as carbonates. It is practically free of chlorine. It is also a product of the German potaslı mines.

Wood Ashes contain more or less potash, which is present chiefly in the form of carbonate.

There are several very inferior sources of ammonia, such as hair, houf meal or horn-dust, leather scrap or meal, etc. While all these materials contain much ammoria, they decay so slowly in the soil that they have a very uncertain fertilizer value. These substances are from their very nature slow to decompose, and when used with other materials, are sure to cause disappointment from the lack of available am. monia to accompany the potash and phosphoric acid.

\section{TERMS USED IN STATING FERTILIZER ANALYSES.}

Fertilizer dealers, and the Experiment Stiition Bulletins treat the different forms of fertilizer materia!s separately and it is important that the farmer should be familiar with these trade names, and understand what they mean. 
The rollowing list contains most of the terms used in stating fertilizer analyses:

Ammonia is expressed as

(a) Nitrogen, (b) Ammonia, (c) Nitrogen equal (or equivalent) to Ammonia.

Phosphoric Acid is expressed as

(a) Phosphoric Acid, (b) Soluble Phosphoric Acid, (c) Reverted Phosphoric Acicl, (d) Available Phosphoric Acid, (e) Soluble and Available Phosphoric Acid, $(f)$ Insoluble Phosphoric Acid, $(g)$ Total Phosphoric Acid, (h) Phosphoric Acid equal (or equivalent) to Bone Phosphate of Lime.

Potash is expressed as

(a) Potash, (b) Potash (actual), (c) Potash S. (or Sul.), (d) Potash (Soluble), (e) Potash as Sulphate, $(f)$ Potash equal (or equivalent) to Sulphate of Po:ash, $(g)$ Sulphate of Potash, (h) Potassium Uxide.

Nitrogen. (Ammonia).

(a) Nitrogen is a gas and, in this form, cannot be used in fertilizers. Therefore, whenever we speak of nitrogen in fertilizers we do not mean that nitrogen exists in them as simple nitrogen. The nitrogen in fertilizers is always combined with other elements, and may be present in one or more different forms: (Ist) in the form of Nitrates, as nitrate of soda; (2nd) in the form of ammonia compounds, as sulphate of ammonia; and ( $3 r d)$ in the form of organic matter, animal or vegetable, as dried blood, meat, tobacco stems, eic. Chemical analysis according to officia?. methods does 


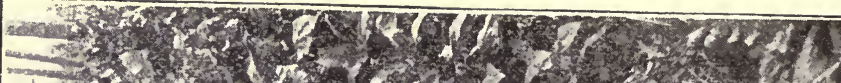

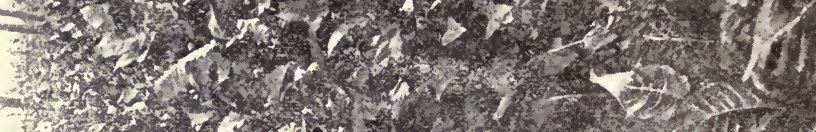

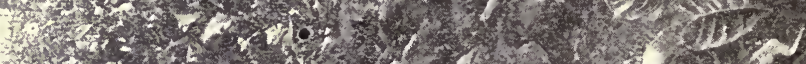

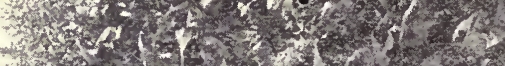

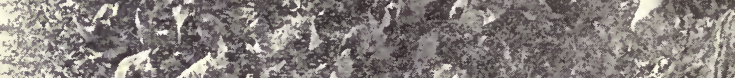

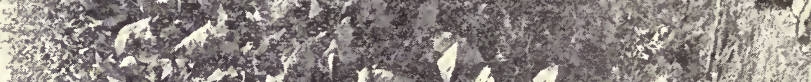

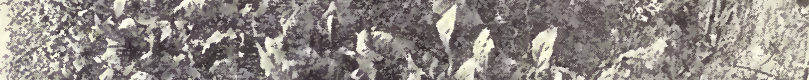

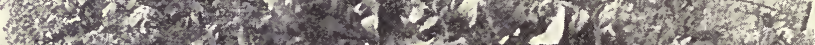

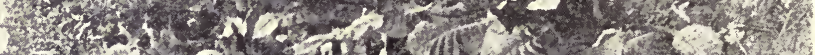

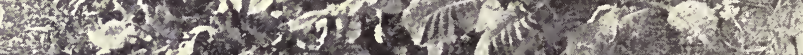

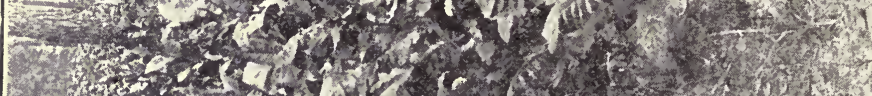

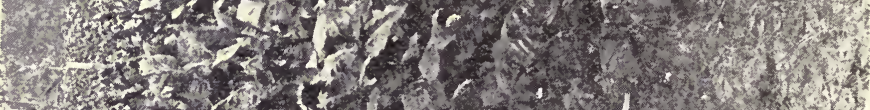

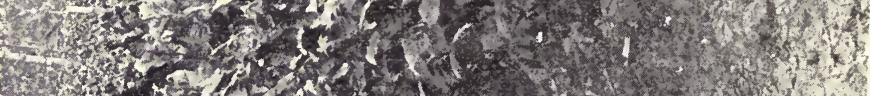
(2)

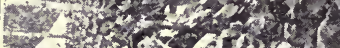

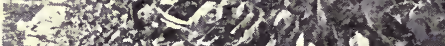

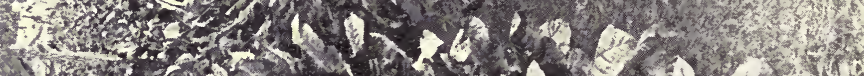

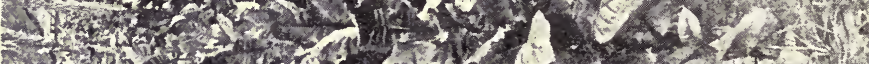
7 . 1. y.x-y $7^{2}-2+3$ 3.

-3)

W.t. -

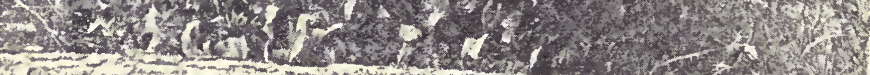

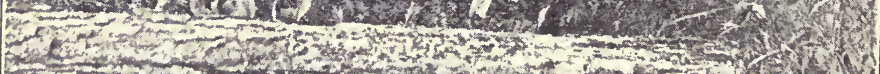

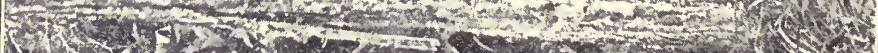

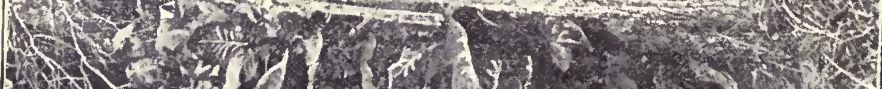


not atteinpt to ascertain and state in which form or forms the nitrogen is present in a fertilizer.

When, therefore, nitrogen is expressed in an analysis or gruarantee as "ammonia," it refers to the entire amount of nitrogen present without regard to the particular form or forms in which it is present.

(b) Ammonia consists of nitrogen combined with hydrogen. A pound of nitrogen will form more than a pound of ammonia, because the ammonia formed from a pound of nitrogen will contain that pound of nitrogen plus the necessary amount of hydrogen added to form ammonia. The chemical relations of nitrogen and ammonia are such that r 4 pounds of nitrogen will unite with exactly 3 pounds of hydrogen, and will, therefore, produce just 17 pounds of ammonia; or one pound of nitrogen will make $1.2 \mathrm{r} 4$ pounds of ammonia.

(c) Nitrogen (equal or equivalent) to Ammonia is a form of expression which simp'y means that the nitrogen is stated not as nitrogen but as ammonia.

It would be better on every account if all guarantees stated simply nitrogen and never mentioned ammonia at all. As a matter of fact, cumpounds of ammonia are quite uncommon in commercial fertilizers, because nitrogen in this form is the most expensive and, therefore, least used. Strictly speaking, the term ammonia should never be used except when sulphate of ammonia or some similar compound is present in the fertilizer. 


\section{PHOSPHORIC ACID.}

(a) Phosphoric Acid, as used in connection with fertilizers, is a compound containing phosphorus and oxygen, which in fertilizers is never found by itself, but in combination with lime. Phosphoric Acid stands for a certain amount of phosphate of lime. IVe may say roughly that one part of phosphoric acid is equivalent to about two parts of phosphate of lime. But we know that phosphoric acid exists in several different forms.

(b) Soluble Phosphoric Acid represents the amount of phosphate of lime that dissolves easily in water; it is formed by treating with-sulphuric acid some form of insoluble lime phosphate, such as bones, phosphate rock, etc. The phosphatc thus formed is readily soluble in water.

(c) Reverted Phosphoric Acid is formed from soluble phosphoric acid under certain conditions into which we need not inquire here. Suffice it to say that the soluble compound of phosphoric acid often changes to some extent, on standing, into a form, which while less soluble, is still quite readily available as plant food.

(d) Available Phosphoric Acid includes both the soluble and reverted forms of phosphoric acid, because both forms are available for the use of plants.

(e) Soluble and Available Phosphoric Acid is an expression which means the same as available.

( $f$ ) Insoluble Phosphoric Acid represents the form of phosphoric acid in raw phosphate of lime, and which is of least value for agricultural purposes. 


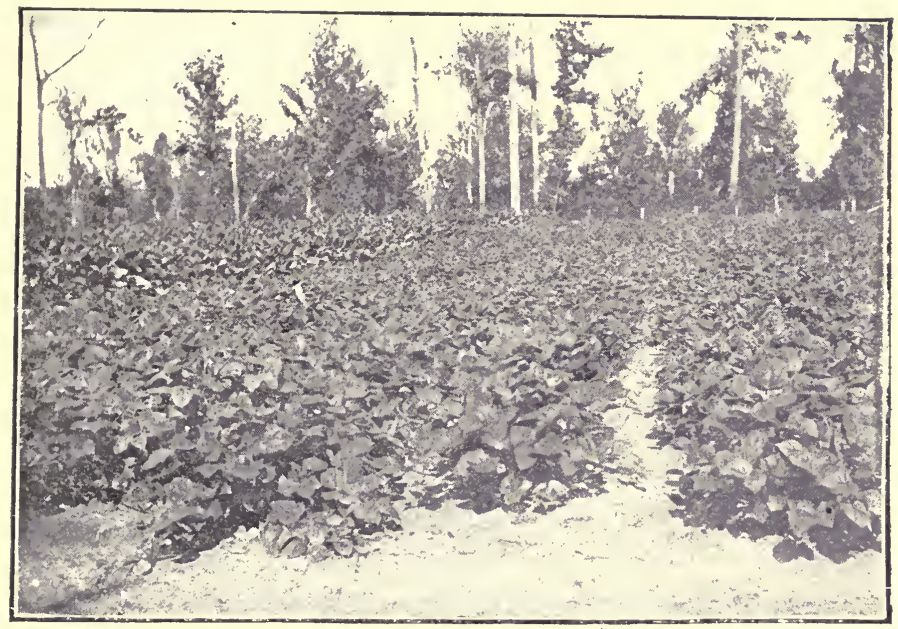

TOBACCO. ROTATION EXPERIMENT, COW PEAS FOLLOWING TOBACCO. FLORIDA EXPERIMENT STATION. 
(g) Total Phosphoric Acid represents the entire phosphoric acid compounds without regard to the forms in which they exist. The total phosphoric acid is, therefore, the sum of the soluble, reverted and insoluble forms; or, to state it in another way, the sum of the available and insoluble forms.

\section{(h) Phosphoric Acid equal (or equivalent) to Bone} Phosphate of Lime is an expression which usually means nothing more or less than insoluble phosphoric acid.

\section{POTASH。}

(a) Potash, as used in connection with fertilizers, al. ways means a compound containing potassium and oxygen, known chemically as potassium oxide. Potash is never tound as such in fertilizcrs, but chemists, when expressing the results of analyses use this form as a convenient standard for reference. Fertilizers generally contain potash in such forms as sulphate of potash, muriate of potash, or carbonate of potash. Instead of stating the amount of sulphate, muriate or carbonate of potash present in a fertilizer, in giving the results of analyses, its equivalent amount is stated only in the form of actual potash.

(b) Potash actual is simply another name for potash, as distinct from sulphate, muriate, etc.

(c) Potash S. (or sul.) means sulphate of potash. This is quite often used by manufacturers in giving guarantees.

(d) Potash soluble represents the amount of potash 
that dissolves in water and is available for the use of plants. The different forms of potash commonly used in fertilizers are readily soluble in water.

(e) Potash as Sulphate means simply sulphate of potash.

( $f$ ) Potash equal (or equivalent) to Sulphate of Potash is an expression which means simply sulphate of potash.

$(g)$ Sulphate of Potash signifies that this compound is actually present in the fertilizer, and that there is no muriate present

(h) Potassium Oxide means the same as potash, or actual potash

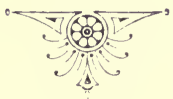


TOBACCO CULTURE.

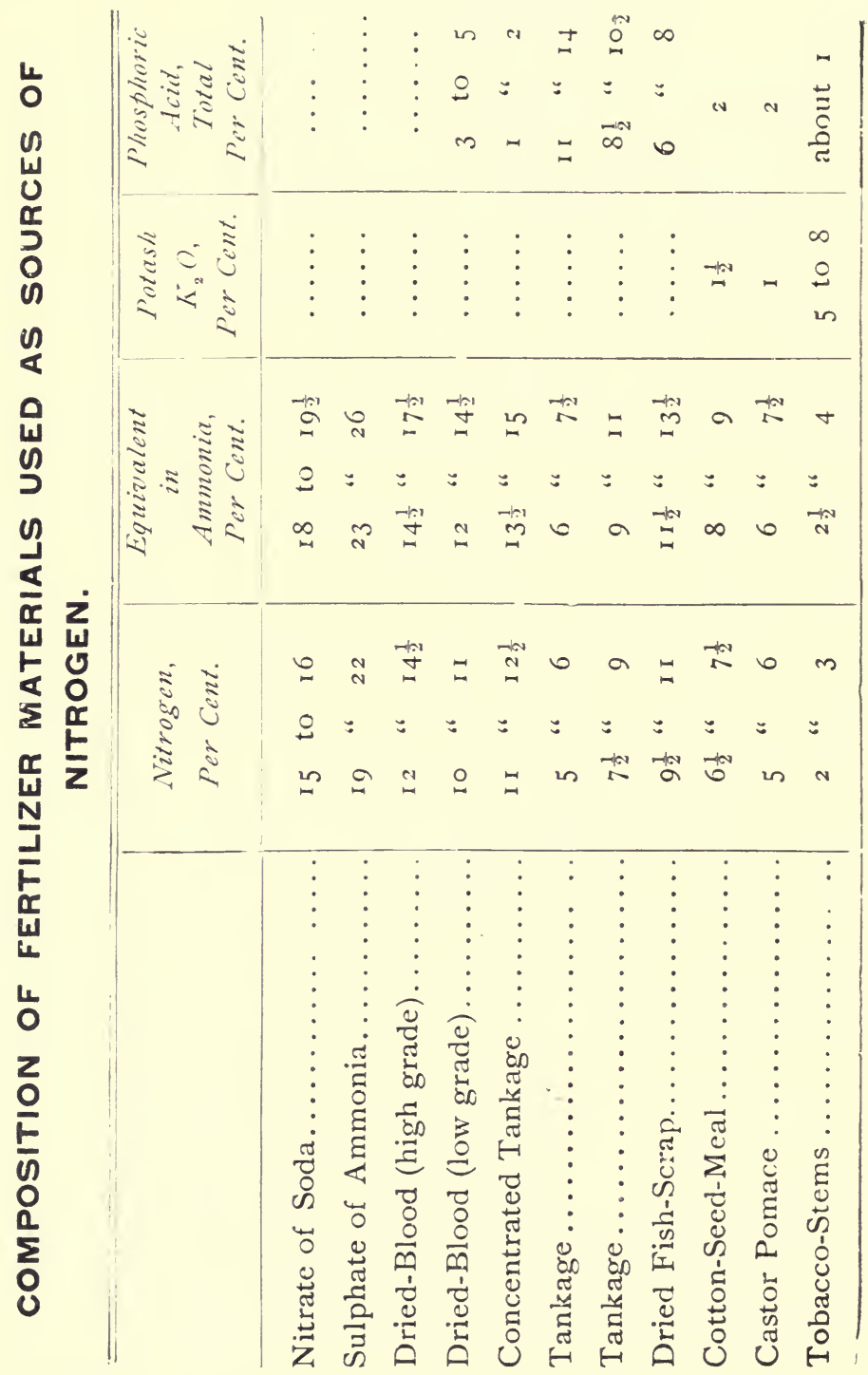




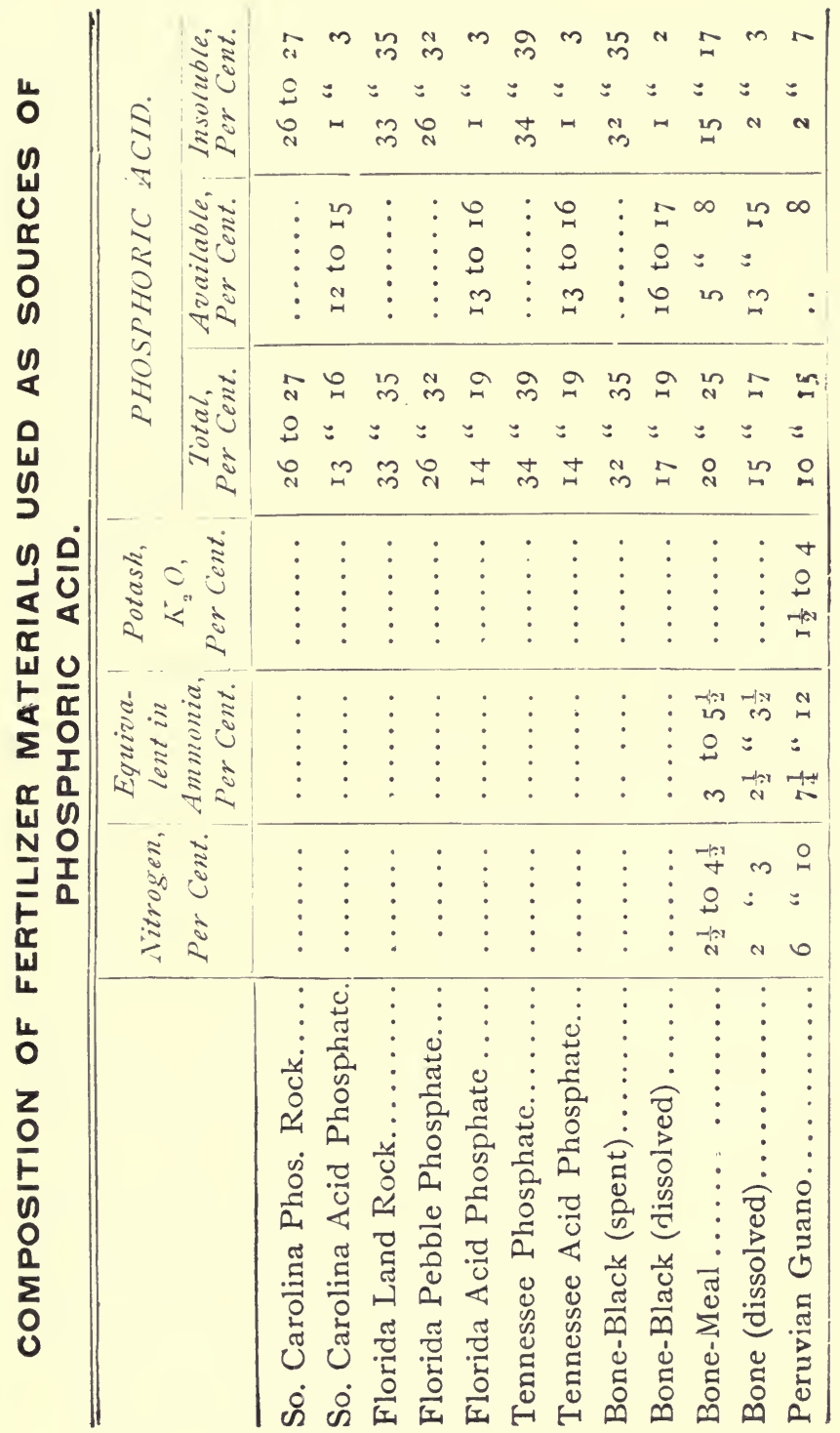






\section{UNIVERSITY OF CALIFORNIA LIBRARY BERKELEY}

Return to desk from which borrowed.

This book is DUE on the last date stamped below.

$3 \operatorname{Jan} 50 \operatorname{CSA}$

$9 A P R O I+B$

MAR 18197545

198.

whe. UR TEB $18^{\circ} 75$

LD 21-100m-9,'48(B399s16) 476 
